\title{
Measles, the need for a paradigm shift
}

\author{
Emilie Javelle ${ }^{1,2,3}$ (P) Philippe Colson ${ }^{2,4} \cdot$ Philippe Parola $^{2,3} \cdot$ Didier Raoult ${ }^{2,4}$
}

Received: 17 July 2019 / Accepted: 3 October 2019 / Published online: 17 October 2019

(c) Springer Nature B.V. 2019

\begin{abstract}
Measles vaccination schedules and targets of herd immunity have been designed according to the paradigm that the vaccine is as protective as natural infection, and the virus has remained of a single serotype over many decades. As a result, ongoing measles resurgence is mostly attributed to gaps in immunization. Using official data, we investigated the correlation between the rate of vaccine coverage reported and aggregated at the national level, and the incidence of cases. We discussed the limits of this indicator considered in isolation. We provide a literature overview of measles vaccine efficacy and failures. We questioned whether measles strains could escape the vaccine. Immunization tools and strategies for measles control deserve to be optimized in the current context.
\end{abstract}

Keywords Measles vaccine $\cdot$ Efficacy $\cdot$ Immunization $\cdot$ Coverage $\cdot$ Genotype

\section{Introduction}

The goal of measles eradication was first set in 1982 [1]. To date, despite measles virus-containing vaccine (MCV) available since the 1960s, only one World Health Organization (WHO) region, the Americas, has achieved measles elimination, i.e., the absence of continuous disease transmission for greater than 12 months. The 2011 Global Vaccine Action Plan has targeted measles elimination in the five other regions by 2020 [2]. However, by mid-2019, the virus is increasingly circulating worldwide. Over the past year (February 2018 to January 2019), 324,277 measles cases were reported to WHO, compared with 172,939 cases in 2017. In 25 countries (15\%), the annual incidence was over

Electronic supplementary material The online version of this article (https://doi.org/10.1007/s10654-019-00569-4) contains supplementary material, which is available to authorized users.

Emilie Javelle

emilie.javelle@gmail.com

1 Laveran Military Teaching Hospital, 34 Boulevard Alphonse Laveran, 13013 Marseille, France

2 IHU-Méditerranée Infection, 19-21 Boulevard Jean Moulin, 13005 Marseille, France

3 IRD, AP-HM, SSA, VITROME, Aix Marseille University, Marseille, France

4 IRD, AP-HM, SSA, MEPHI, Aix Marseille University, Marseille, France
50 per million total population, and the highest rates $(>150$ cases per million) were recorded from all continents [3].

The ongoing measles resurgence has come in the media spotlight. Intentionally unvaccinated people are blamed, while old and new controversies against MCV have flared up with pejorative effects. In February 2019, unvaccinated French travellers imported the measles virus to Costa Rica after a gap of more than 12 years with no recorded endemic cases [4]. At once, the French family was placed in isolation, out of fear of measles virus reintroduction and outbreak despite a locally declared high vaccine coverage, as has happened in other countries $[5,6]$. Thus, measles control requires joint efforts across various fields.

\section{Methods}

We reviewed references from the PubMed database through April 2019 by an advanced search for the terms "measles vaccine" and "failure" and selected those judged relevant. We also made focused searches for "measles vaccine" and key words "coverage" or "protection" or "efficacy" or "effectiveness" or "immune response" or "immunogenicity" or "neutralizing antibody" or "third dose" or "genetic" or "genotypes" or "molecular". We selected recent publications and commonly referenced papers in the field (referent authors and most cited articles). We cross-checked the references of the articles we selected. We included articles in English, 
French and German. We searched for "measles" and "vaccine" at ClinicalTrials.gov through April 2019 and selected completed trials with results. We consulted the databases, datasets and official reports of the WHO and Centre for Disease Control (CDC) on their official websites and the mentioned references. We used data on measles cases per month and year collected by the WHO from 194 countries, and we used the world population prospects from the United Nations to calculate incidence rates. We also reviewed coverage estimates for the second dose of measles containing vaccine (MCV2) at the nationally recommended age provided by the WHO/UNICEF Estimates of National Immunization Coverage (WUENIC) [3]. We used the software tools Excel, $\mathrm{R}$ version 3.5.1 (2018-07-02), Adobe Illustrator 22.1, and MEGA6 for analyses.

\section{Vaccine coverage and its correlation with measles incidence}

Several attempts have been made to model the effects of measles vaccination schedules. A bulletin from WHO published in 1993 [7], based on the work of Hethcote [8], showed that with a vaccine efficacy of $95 \%$, a coverage of more than $98 \%$ for one dose, or $84 \%$ for one dose and $80 \%$ for the second dose, would likely interrupt measles transmission. To date, the recommended population-level immunity is $95 \%$ by the age of five to meet the goal of measles elimination. This target was validated in a recent work (waiting for peer review) from the London School of Hygiene \& Tropical Medicine, with WHO and CDC, comparing the estimated immunity levels from serological data in 17 countries, with the incidence of cases recorded in the 10-year period following the serological studies [9]. Importantly, the plain immunity level was not enough to predict whether countries would experience outbreaks. Among the 17 countries, six $(35 \%)$ outliers in the correlation between immunity levels and case burden were identifiable in the two positive and negative directions. Latvia and Lithuania, with $71 \%$ and $91 \%$ contact-adjusted immunity levels, recorded 0.72 and 1.7 mean annual cases per million over the 10 years, respectively, whereas Spain and Israel, with $95 \%$ and $94 \%$ contactadjusted immunity levels, presented 8.6 and 30 mean annual cases per million over 10 years, respectively. Additionally, the United Kingdom and Romania, both with $92 \%$ contactadjusted immunity levels, documented 10 and 93 mean annual cases per million over the period, respectively. Such discrepancies are observable worldwide.

\section{Recent data}

Figure 1 shows the evolution of MCV2 coverage during the last decade per WHO region based on the average reported coverage by 135 countries for the two five-year periods (2008-2012) and (2013-2017) (details per country in supplementary files S1 to S6). Globally, MCV2 coverage has improved with time. It has remained above 95\% from 2008 to 2017 in Albania, Bahrain, Belarus, Cuba, Democratic Republic of Korea, Hungary, Iran, Kazakhstan, Kyrgyzstan, Oman, Republic of Korea, Russian Federation, Saudi Arabia, Seychelles, Slovakia, Sri Lanka, Tunisia, and Turkmenistan. For 17 of these countries, Fig. 2 represents the annual measles incidence per million during that period. Kyrgyzstan saw its largest outbreak in 2015 with more than 17,779 cases

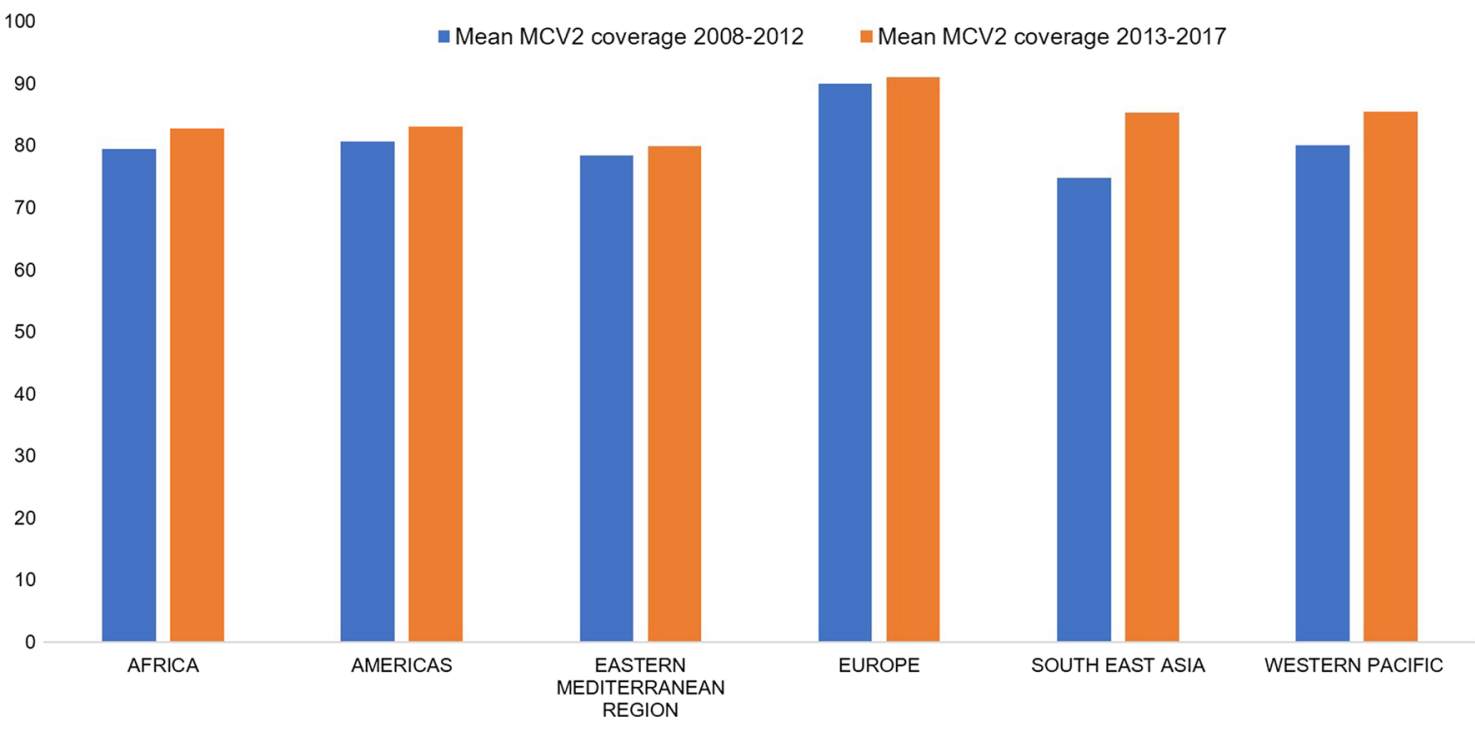

Fig. 1 Evolution of the immunization coverage with second dose of measles containing vaccines per WHO regions during the last 10 years: average coverage over the five-year periods 2008-2012 and 2013-2017, based on the report of 135 countries to WHO 
Fig. 2 Annual measles incidence rate per million during 2008-2017 in 17 countries that sustained coverage with second dose of measles containing vaccines above $95 \%$ during this 10 year-period, WHO data

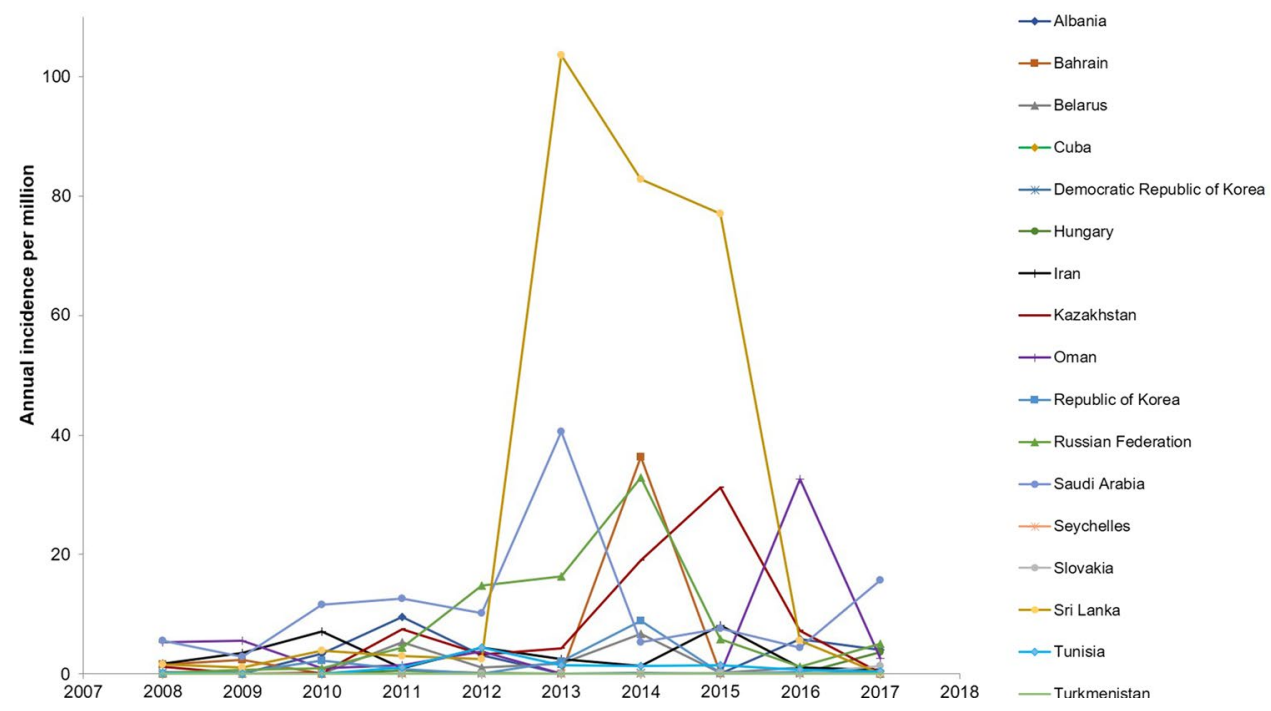

reported, leading to an annual incidence over 3000 cases per million. Due to this extreme value, for greater clarity, Kyrgyzstan is not represented on Fig. 2. This graph shows that despite MCV2 immunization coverage sustained at the recommended level over ten years, outbreaks also occurred in Russia (2014), Bahrain (2014), Sri Lanka (2012-2015), Oman (2016), and Saudi Arabia (2013 and 2017). Drawing on the work of Funk et al. [9], we drew MCV2 coverage in 2009 versus the mean annual incidence of measles per million total population over the period 2009-2018. Coverage with MCV2 in 2009 was available for 123 countries. The median coverage was $92 \%$, ranging from 6 to $99 \%$, and the median annual incidence was 10.8 per million, ranging from 0 to 1732.6 (Fig. 3). Notably, despite an MCV2 coverage rate of $97 \%$ in 2009, Mongolia had the highest mean annual incidence over the following decade (1732.6 per million). Indeed, after the virus was declared eliminated from the country in 2014, Mongolia experienced a severe measles outbreak with a strain imported from China in 2015-2016, a period during which MCV2 coverage was 96\% [10]. The most recent data we had for MCV2 coverage concerned 2017 and 162 countries. In Fig. 4, we overlaid the distribution of MCV2 coverage in 2017 with the measles mean annual incidence rate per million so far (based on the total measles cases reported by countries from January 2017 to March 2019). Notably, the countries with MCV2 coverage above 95\% experienced similar or even higher incidence rates than areas with MCV2 coverage below 50\%, such as Albania, Israel, Kyrgyzstan, Malaysia, Kazakhstan, Thailand, Slovakia, Bhutan, Tajikistan, Saudi Arabia, the former Yugoslav Republic of Macedonia, Bangladesh, the United Arab Emirates, Belarus, the Russian Federation, and Portugal. Thus, MCV2 coverage is not strongly correlated with the risk of local outbreaks and has some limit to guarantee measles elimination.
Fig. 3 Average annual measles incidence rate per million during the last 10 years (2009-2018) according to the coverage with second dose of measles containing vaccines (MCV2) at the start of the period (2009) reported to WHO by 123 countries from the African region (AFR), the Americas (AMR), the Eastern Mediterranean Region (EMR), Europe (EUR), the South-East Asia Region (SEAR), and the Western Pacific Region (WPR)

\section{Vaccine coverage assessment}

By the end of 2017, the global coverage with one dose of MCV was $85 \%$ (reached and maintained since 2011), and $167(85 \%)$ countries had included a second dose as part of routine immunization, leading to a global coverage with two doses estimated by WHO to be $67 \%$.

First, vaccine coverage rates do not involve all age groups and are self-reported by countries to WHO and UNICEF through the "Joint Reporting Form" via e-mail, which limits their interpretation [11]. Basically, three methods exist to estimate vaccine coverages [12]. The annual collection

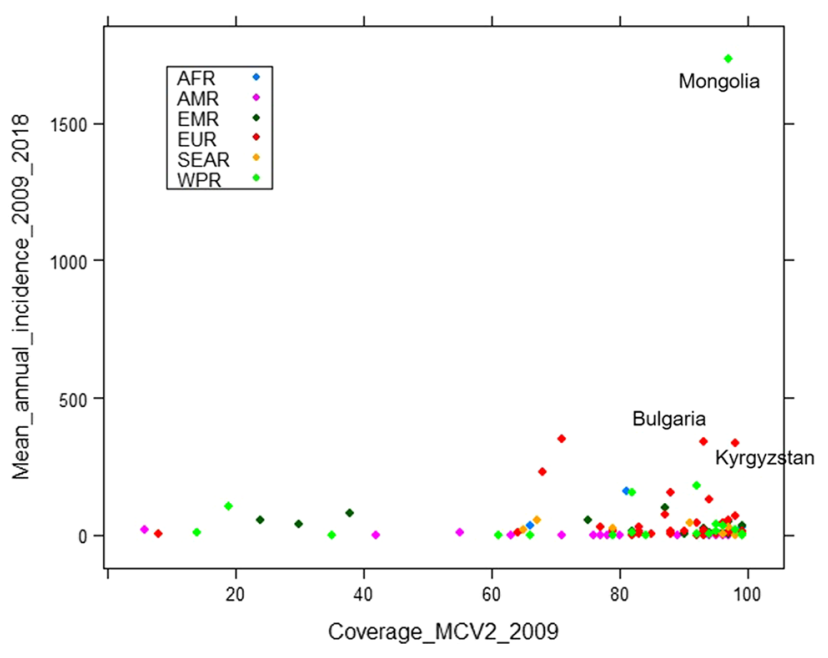




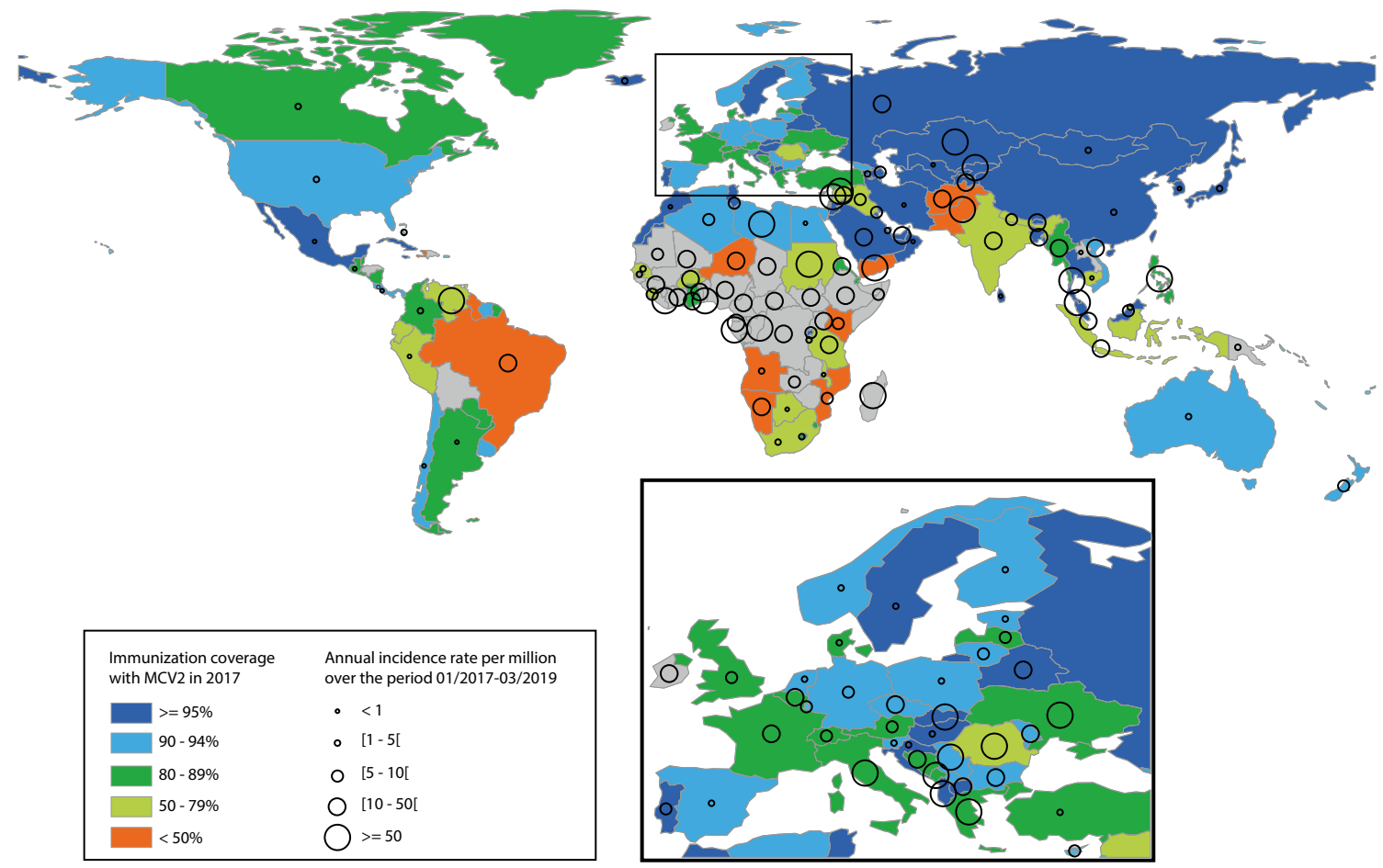

Fig. 4 Immunization coverage with second dose of measles containing vaccines (MCV2) in 2017 and the average annual measles incidence rate per million during the last 27 months (01/2017-03/2019), WHO data

of national administrative reports is the easiest process, but depends on recording system reliability. Country site visits by epidemiologists, vaccine programme managers, and health workers to interview health authorities, practitioners, and parents, are a second means of investigation. A third, more technically challenging method, is the conduction of vaccine coverage surveys following the WHO cluster survey model ( 30 clusters of 7 individuals in the 2015 version) to randomly select a representative probability-based sample [13]. All these strategies are based on records and recalls that may-intentionally or not-be erroneous. Coverage assessments can be complemented with serological surveys but with substantial limits: biomarkers do not distinguish between antibodies generated by vaccine and natural infection; the number of doses received is not provided; and the absence of detectable antibodies does not necessarily mean that the individual was never vaccinated. Thus, vaccine coverage approximates should be confirmed with other data, such as vaccine national consumption and sales.

\section{Unvaccinated people}

In many areas experiencing measles resurgence, such as France [14], the incidence is very high in children less than 1 year old who are not eligible for vaccination in accordance with current schedules. For example, this age group represented 16\% of cases in Bulgaria in 2009-2011 [15],
$19 \%$ of cases during the massive 2015-2016 outbreak in Mongolia [10], and 25\% of cases during an epidemic in Portugal in 2017 [16]. During an Italian outbreak in 2017, 44\% of cases occurred in children less than 15 months of age [17]. In 2018, 8\% of all cases reported from the European region were in children younger than 1 year, which represented more than 6600 cases [18]. Likewise, in a Chinese province, the proportion of cases in children less than 1 year old has increased over time to almost 50\% [19]. In Brazil and Colombia, where the highest incidence rate is among children under 1 year old, vaccination campaigns targeting 6-month-old children have been implemented [20, 21].

In countries displaying correct national coverage of MCV2, pockets of unvaccinated people persist in rural areas, cities with high poverty rates, among migrant populations [2] or other communities, such as Amish in Ohio [22], ultraOrthodox Jewish in New York [23], Orthodox Protestants in the Netherlands [24], or Roma in France [25] and Bulgaria [26]. Most ongoing epidemics are occurring in unimmunized communities [27]. Moreover, it may be difficult to identify and provide a full accounting of people refusing vaccination. For example, as clinicians, we experienced patients presenting at the vaccine consultation who ask for a false injection (outside the arm) and a false certificate.

Therefore, in some areas, vaccine shortages have made the coverage worse, as in Ukraine in 2016, a year when only $42 \%$ of infants were vaccinated [28], and currently in 
Madagascar, Chad and New Zealand [29]. Conflicts and wars also play a role in vaccine-preventable disease resurgence by disrupting health and prevention systems [30], as currently observed in Yemen [31] and Venezuela [32]. Finally, regional and global travel has significantly amplified the risk of importation and spread of the virus within susceptible areas and has re-introduced the disease in areas free of endemic transmission [29, 33, 34].

Thus, vaccination coverage is currently suboptimal to stop measles virus circulation. Nevertheless, the paradox of concurrent improving trends in immunization rates and increasing measles incidences questions whether targeting and maintaining high vaccination coverage is a sufficient approach. Notably, the vaccine coverage threshold that would be necessary to establish herd immunity and prevent epidemics due to imported or indigenous cases depends on vaccine efficacy [35].

\section{Vaccine effectiveness}

Historically, measles live-attenuated vaccines were formulated with the idea that a single dose administered to an immunocompetent individual would induce similar immune responses as those of natural disease, providing the benefit of life-long protection without the disadvantages of primoinfection. However, to date, one injection of MCV is not considered protective enough (with a two-dose regimen recommended also in unvaccinated adults [36]), whereas measles infection at any age always provides long-term protection against all wild-type viruses.

Measles virus was first isolated in 1954 from the blood of a boy named David Edmonston [37]. Most of the currently widely used vaccines (Moraten in the USA, EdmonstonZagreb in developing countries and Schwarz in many other countries) are derived from this original wild-type viral strain, the so-called Edmonston strain, which was used in the first attenuated measles vaccine, Edmonston B, licensed in 1963 [38]. Other non-Edmonston-derived attenuated measles vaccines have been produced from locally derived wild-type strains during the same period in the Russian Federation (Leningrad-16), China (Shanghai-191) and Japan (CAM-70, AIK-C) [29].

\section{Antigenic features of measles virus}

Measles virus is a member of the genus Morbillivirus in the family Paramyxoviridae. Its single-stranded RNA genome is around 15,000 nucleotides in size and encodes at least eight structural proteins [39]. The most abundant and rapidly produced antibodies are against the nucleoprotein $(\mathrm{N})$, but the host immunity depends mostly on developing polyclonal neutralizing antibodies to the $\mathrm{H}$ and $\mathrm{F}$ glycoproteins, with the $\mathrm{H}$ proteins inducing strong and long-term immunity [40]. Although RNA viruses usually have a high mutation rate, MCV developed in the 1960s would have remained protective worldwide because the virus is antigenically monotypic $[41,42]$. This means that the structure of the $\mathrm{H}$ protein epitopes involved in immune responses has remained relatively preserved over decades [43]. However, the nucleotide sequences of the $\mathrm{N}, \mathrm{P}$ and $\mathrm{H}$ genes are the most variable in the genome, and genetic drift leading to new or modified antigenic determinants were described in the $\mathrm{H}$ protein [44]. In vitro, the $\mathrm{H}$ sequences can tolerate and accumulate significant escape mutations [45]. In addition, based on genetic and antigenic variations in $\mathrm{H}$ and $\mathrm{N}$ sequences, wild-type measles viruses have been divided into eight clades designated $\mathrm{A}$ to $\mathrm{H}$ encompassing each of several genotypes identified by numerals [46]. New genotypes are designated if the nucleotide sequence differs from the closest reference sequence by more than $2.5 \%$ in $\mathrm{N}$ and $2.0 \%$ in $\mathrm{H}$ [47]. As of the 2015 update, 24 genotypes have been determined [48]. The 450 nucleotides encoding the carboxyl-terminal part of the N-protein $(\mathrm{N}-450)$ exhibit up to $12 \%$ diversity and are commonly used to identify the genotypes [46, 48, 49]. Moreover, there are multiple distinct genetic lineages within genotypes that deserve to be more thoroughly characterized by expanding the size of the analysed genomic region [41, 49]. All available vaccines comprise viral strains belonging to clade A, with remarkable sequence similarity despite the diverse geographic origins and the different attenuation methods used [50].

\section{Post-vaccine protection}

The global "effectiveness" of two-dose MCV administered at an appropriate age is usually cited as $95-97 \%[7,51]$. According the CDC/Advisory Committee on Immunization Practices (ACIP), vaccine administered on or after age 12 months is $95 \%$ effective in preventing measles and is $99 \%$ after a second dose [52]. In a literature review of MCV effectiveness studies published during 1960-2010 [53], point estimates for MCV2 ranged from 88 to $100 \%$ but sometimes had wide $95 \%$ confidence intervals [54-56]. This review included 14 papers, but only case-control or retrospective cohort studies. Other case-control studies have provided divergent data from different world areas: MCV immunogenicity was 80\% (95\% CI [60-90\%]) in Bangladesh [57], whereas it was $96.7 \%$ (95\% CI [94.5-98\%]) for one dose and $99.7 \%$ (95\% CI [99.2-99.9\%]) for two doses in Australia [58]. Randomized trials have assessed MCV efficacy through antibody concentrations [59-69] or non-specific effects on all-cause mortality, hospitalization, and growth in low-income countries paediatric populations [70-72]. Essentially, there have been no trials evaluating the clinical efficacy of MCV schedules in preventing measles disease or 
monitoring the long-term quality of the immune response [51]. Table 1 shows the available results from trials registered at ClinicalTrial.gov (Table 2).

At our University Hospital Institute, a 24-year-old resident male vaccinated against measles virus in 1994 and 2003 was diagnosed in February 2018 with secondary measles disease (methods detailed in supplementary files S7). Fourteen days after having been in contact with an infected physician colleague, he developed fever, rhinorrhea, and myalgia, and 3 days after, a rash on the face and the trunk with cervical lymph nodes. He completely recovered within 8 days. His serum sample collected 4 days after the onset of clinical symptoms tested positive for the presence of measles virus-specific immunoglobulin (Ig)G but not IgM. Measles virus real-time quantitative (qRT)-PCR was positive in the oral fluid sample, and genotype D8 was determined (Fig. 5). This case report highlights two major issues.

First, due to the major infectiousness of measles, the question of post-vaccine protection is of particular concern in the most exposed population, such as travellers and health workers [52, 73]. Irrespective of their past immunization status, the relative risk of measles in healthcare workers compared to the community adult population was reported as high as 18.6 (95\% CI [7.4-45.8]) in a study conducted in 1996 in medical facilities in Washington [74]. In addition, nosocomial transmission can amplify measles virus dissemination as it occurred in Bangladesh in 1995-96 [57] or in Mongolia in 2016 [75], with potential severe and fatal consequences in high-risk patients [76], leading to a greater health and cost burden [77].

Second, the documented administration of two-dose MCV cannot be considered as evidence of measles immunity, and a positive serology result cannot predict protection against viral disease. In a retrospective review of WHO global surveillance data, Patel and Orenstein found that $9 \%$ of worldwide measles cases during 2013-2017 were two doses vaccine recipients [78]. In a retrospective review of Californian measles cases from 2000 to 2015, Cherry and Zahn found that $11 \%$ of cases corresponded to vaccine failures after two doses of MCV, which occurred 15 years on average after the last vaccination [79]. During the 2014 outbreak in Micronesia, $40 \%$ of cases occurred in twicevaccinated people [6].

There are two mechanisms responsible for MCV failure. Primary failure arises when a vaccinated individual does not develop a humoral response. Secondary failure occurs when an individual develops specific IgG antibodies after vaccination but exhibits no protection against subsequent infection with a wild-type virus. Secondary failure is characterized by the absence of a primary immune response, i.e., $\operatorname{IgM}$, with the presence of high-avidity virus-specific IgG antibodies at the time of symptomatic acute infection [80]. On the other hand, individuals with low post-vaccination antibody titres might have an adequate response against the virus [41, 81].

\section{Primary vaccine failure}

Children vaccinated between 6 and 15 months of age exhibit a lower response to a dose of MCV due to the immaturity of their immune system and the presence of maternal antibodies [82]. Passive antibodies have a shorter duration when they were acquired after mother vaccination than when they were induced by wild-type measles infection [83]. Their effect constitutes the primary obstacle to vaccine-induced humoral immunity in 9-month-old infants, while immaturity predominates in 6-month-old children [84]. Vaccine humoral response increases with age up to approximately 15 months. This was the immunological basis used by the CDC/ACIP to recommend a second dose of MCV over 1 year of age in 1989 in the context of large outbreaks in the United States [85], before it was officially recommended by the WHO in 1993 [7]. Second doses aimed at immunizing individuals who failed to respond to the first dose and provide the opportunity to vaccinate those who had never received the vaccine. A population-case-control study during the 1988-89 epidemic in Finland included 153 vaccinated serologically confirmed measles cases and demonstrated that subjects vaccinated once had a 5.6 (95\% CI [2.1-18.5]) higher risk of primary failure compared with those vaccinated twice [86]. A recent analysis of vaccine immunogenicity data from European and American trials found a significant difference in post-vaccination antibody titres according to the age at the first dose; however, in all age groups, there were minimal proportions of children who remained non-responders after two doses $(\leq 2.6 \%)$, and no difference in the antibodies was maintained with a remarkable decline over 3 years [82]. However, the risk of failure after a two-dose vaccine was reported to be higher in Canadian students who had received the first dose before rather than after 15 months of age [87]. In a 2016 literature review on the humoral immunity to MCV, two to $10 \%$ of twice-vaccinated individuals were reported to lack protective titres of measles antibodies, which waned over time [88]. In 2007-2008, Gomber et al. followed up 103 consecutive Indian children for over 1 year who were first vaccinated with the measles, mumps, and rubella (MMR) vaccine at 12-15 months and received a second injection at age 4-6 years at the time of inclusion. The pre-vaccination seroprevalence for measles (Demeditec (Germany) ELISA IgG $>12 \mathrm{U} / \mathrm{ml}$ ) was only $20.4 \%$ (but $87.4 \%$ for mumps and $75.7 \%$ for rubella arguing for the reality of the first dose administration) and raised only $65.2 \%$ after two doses [89]. An immunogenicity study in infants aged 8 months in China showed 98-99\% seroconversion after the first measles-rubella vaccination [90]. 


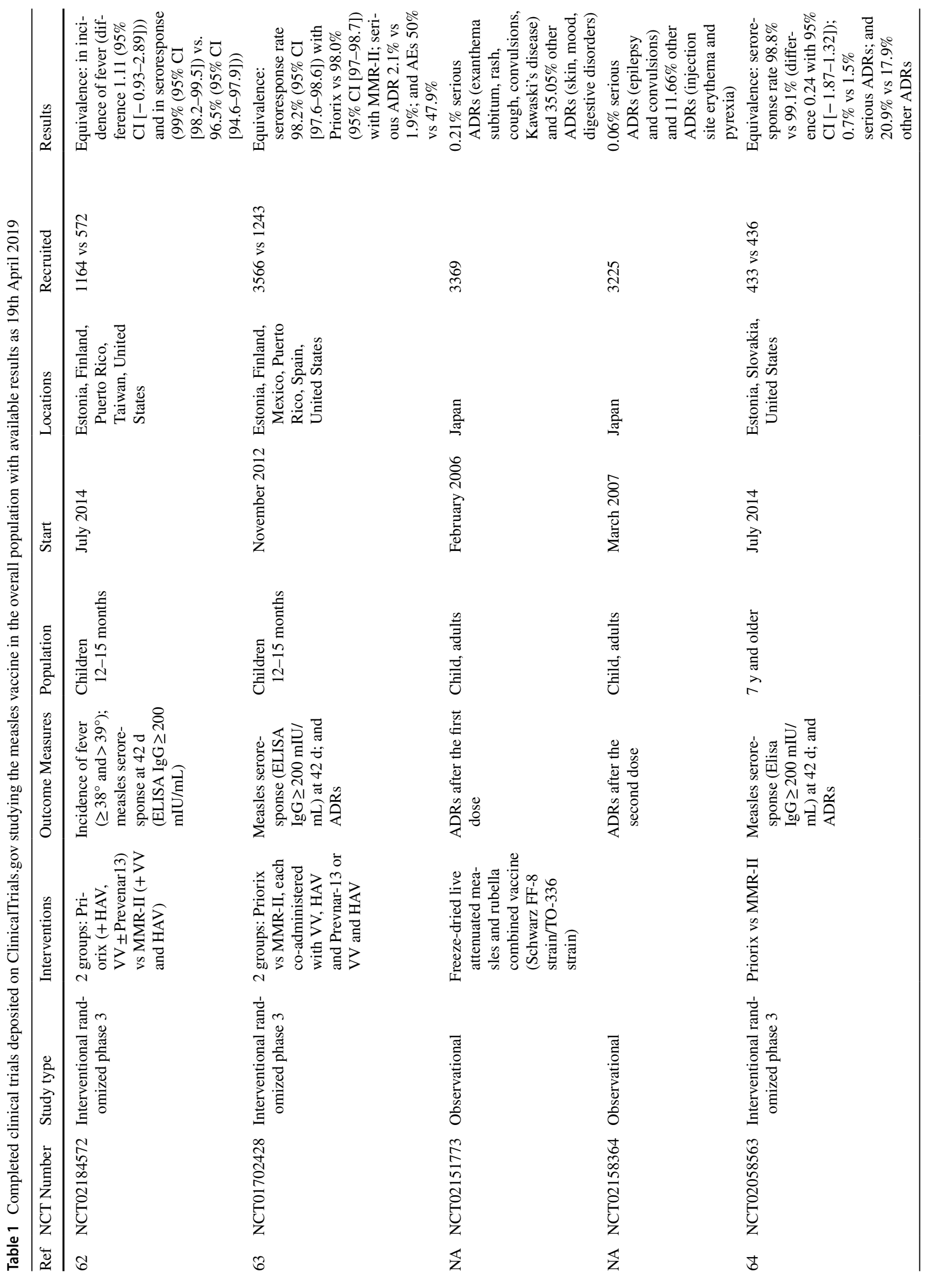




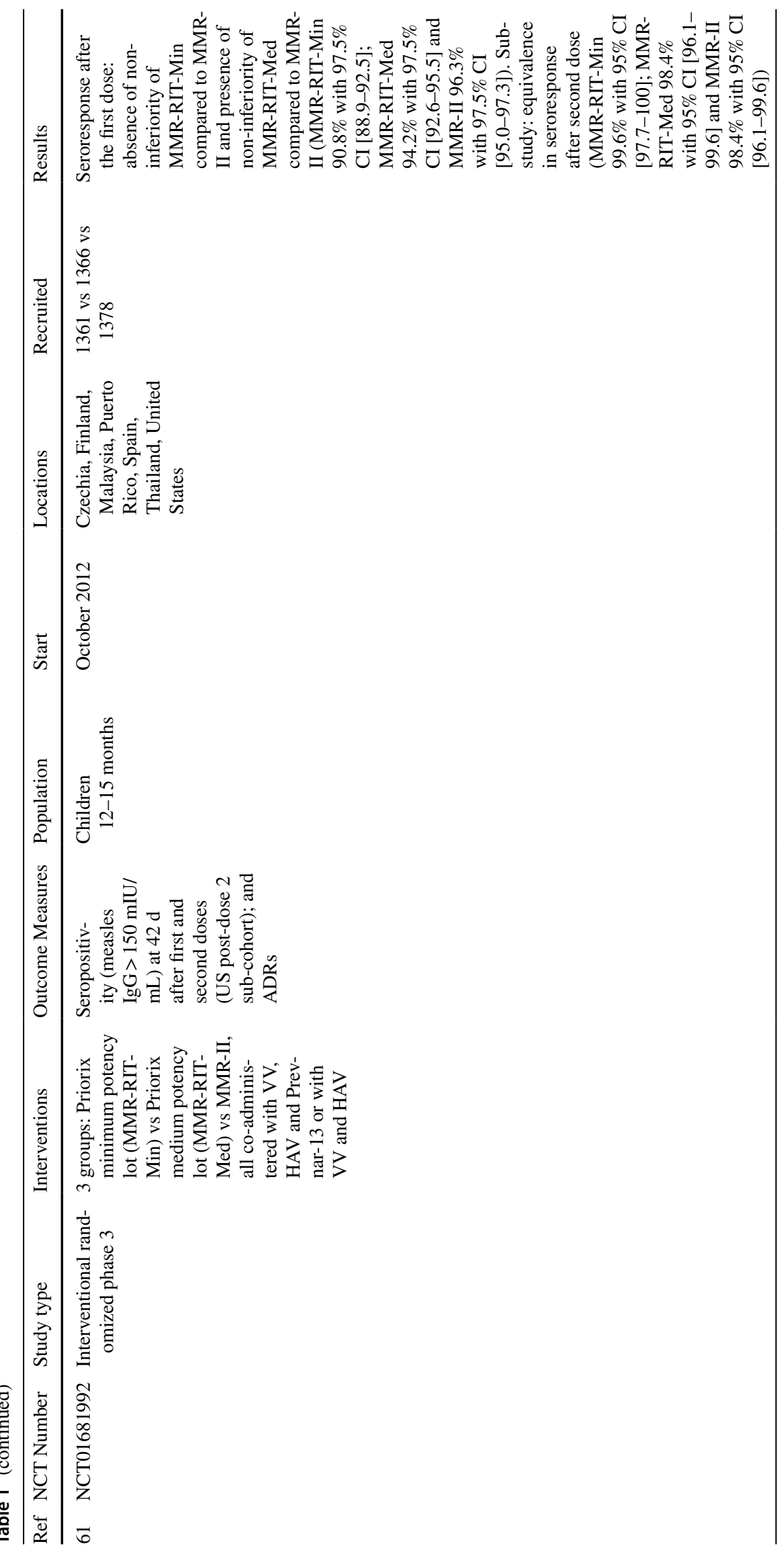

等 Springer 


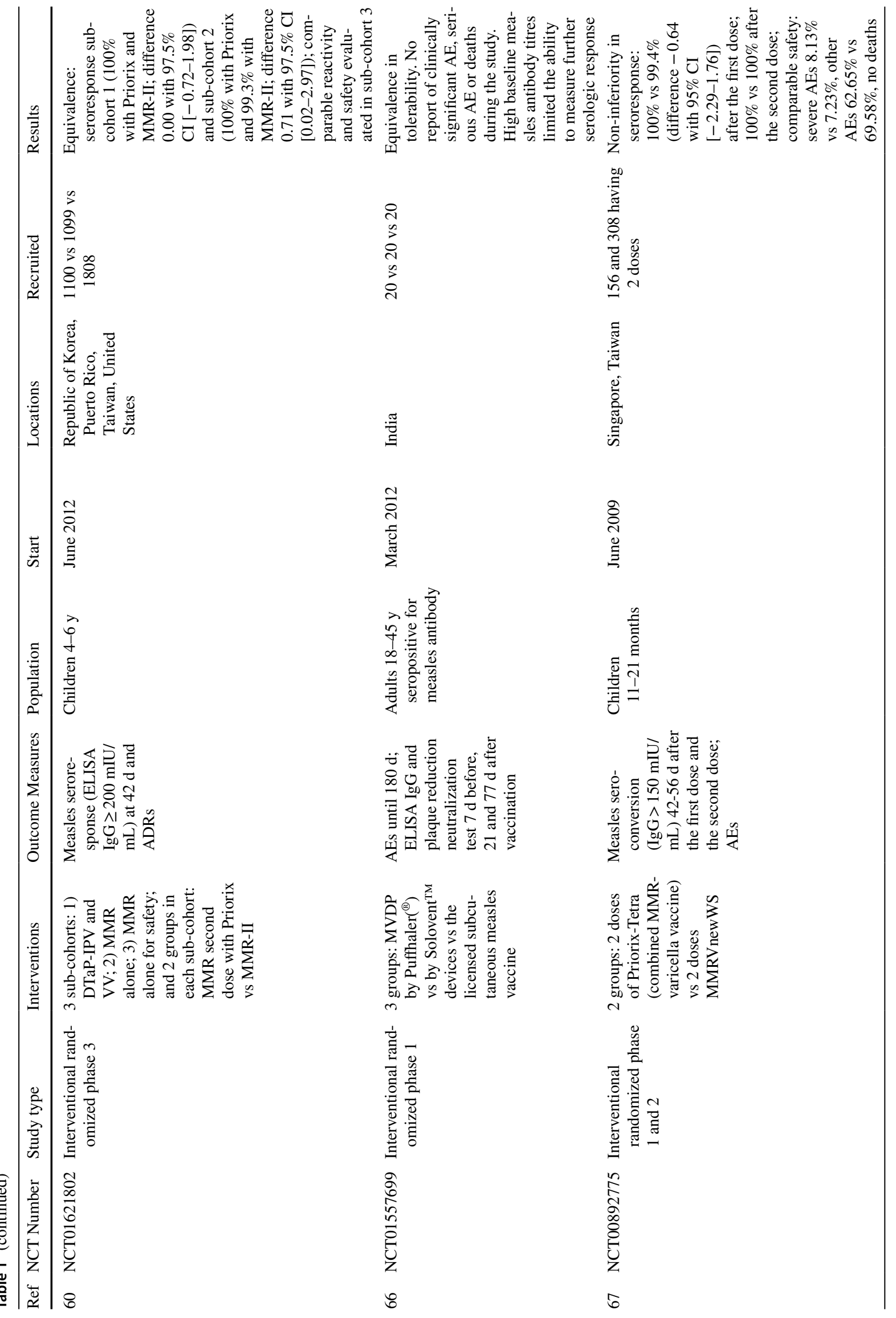




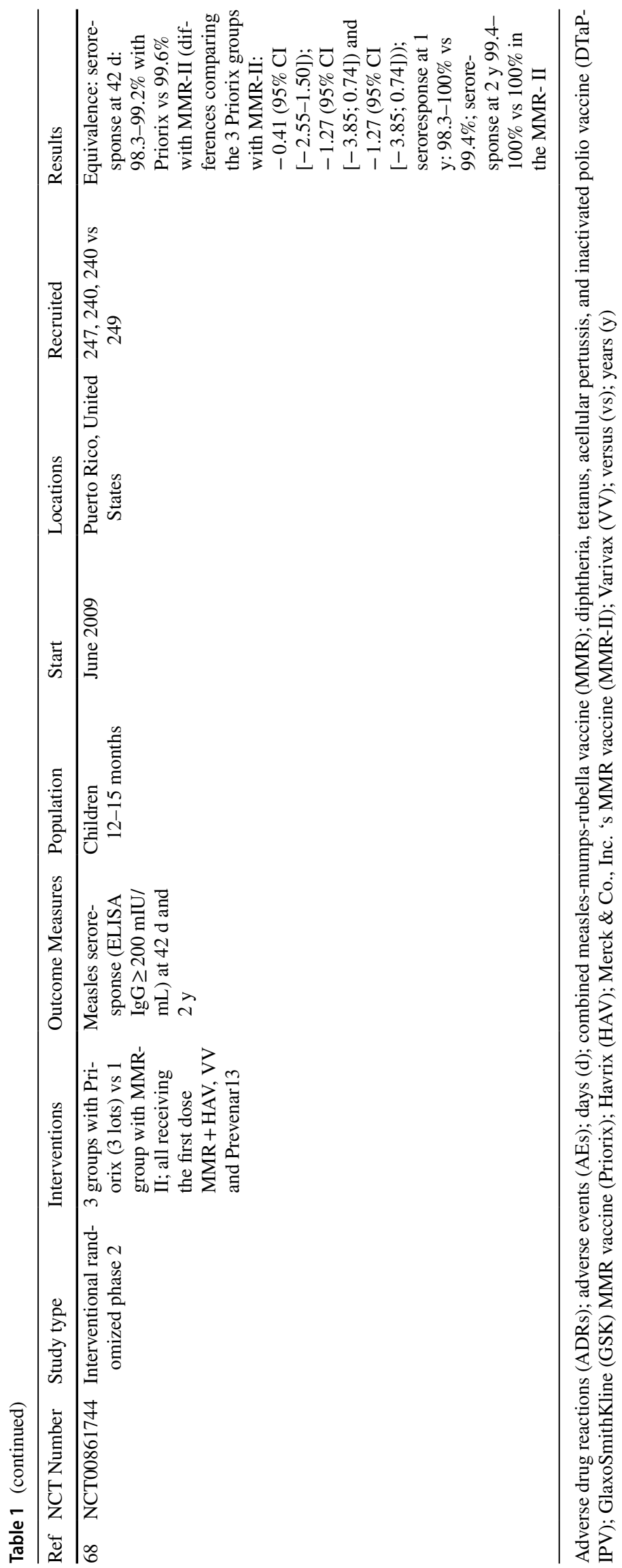




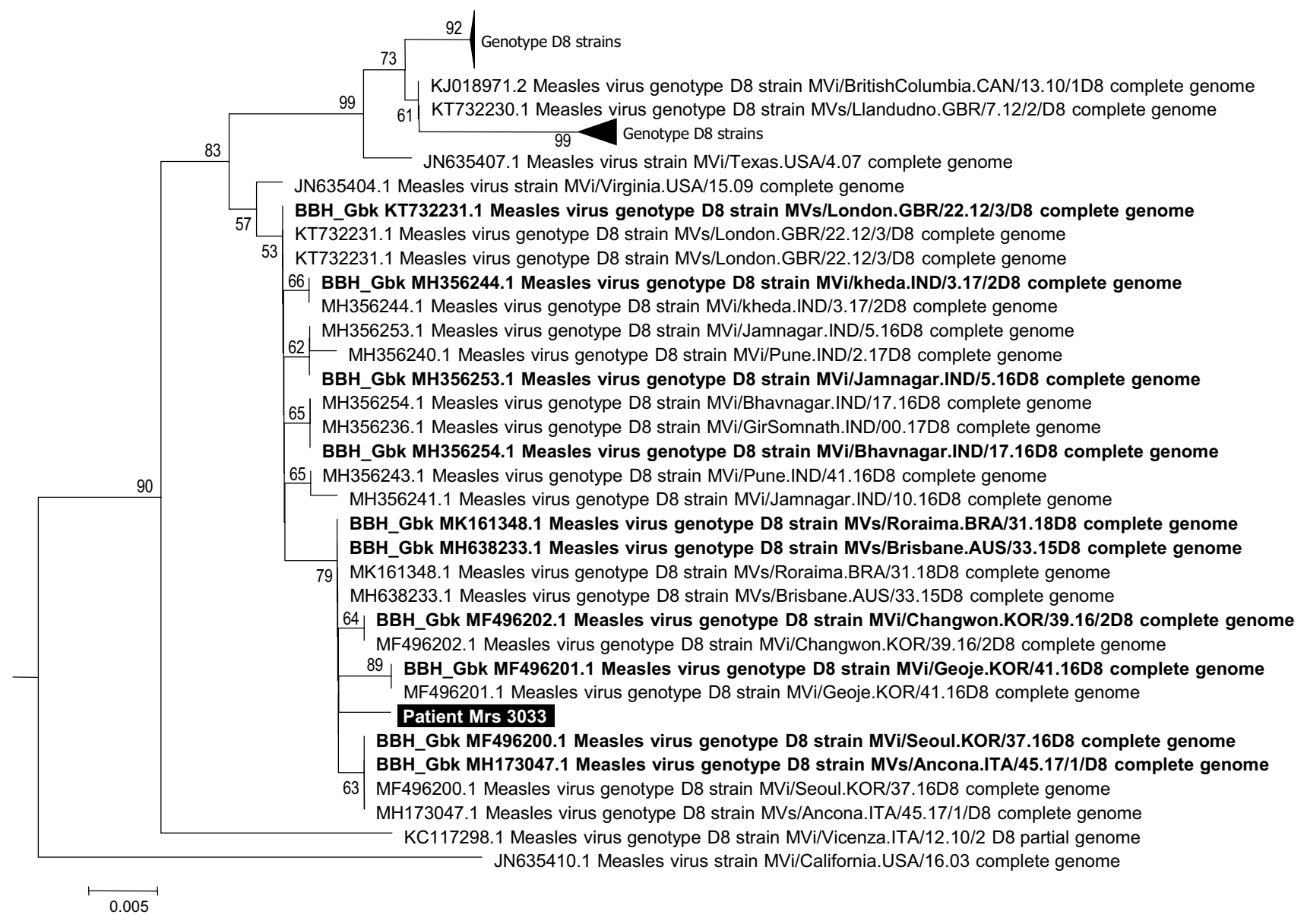

Fig. 5 Case report D8 strain: phylogenetic tree based on the nucleocapsid gene from measles viruses. The fragment of the measles virus genome encoding for the nucleocapsid protein was 531-nucleotide long and corresponded to nucleotides 1155-1685 of the HEV genome GenBank accession no. MH173047.1. The measles virus sequence (GenBank Accession no MK935706) obtained by Sanger population from the case-patient is indicated by a white bold font and a black background. The ten sequences with the highest BLAST scores recovered from the NBCI GenBank nucleotide sequence databases (http://www.ncbi.nlm.nih.gov/nucleotide/), indicated by bold font, were incorporated in the phylogeny reconstruction, in addition to complete genome sequences retrieved from GenBank using "measles virus" and "complete genome" combined as keywords and from

To explain disparities, inter-individual variability in humoral immune responses to MCV has been linked with HLA and non-HLA host genetic factors and with some vaccine receptors or interleukin polymorphisms [88, 91]. Additionally, the quality of vaccines or incorrect documentation of first and/or second dose vaccination must be considered. Notably, in Iran, two distinct Edmonstonbased MCV showed differences in immunogenicity in the first years of life [92], whereas in American randomized trials (Table 1), the MMR-RIT vaccine (Priorix, https://www.who.int/immunization/monitoring_surveillance/burde n/laboratory/manual_chapter7/en/. Nucleotide alignments were performed using the MUSCLE software (http://www.ebi.ac.uk/Tools/ $\mathrm{msa} / \mathrm{muscle} /$ ). The evolutionary history was inferred in the MEGA6 software (http://www.megasoftware.net/) using the Neighbor-Joining method and the Kimura 2-parameter method. The percentage of replicate trees in which the associated taxa clustered together in the bootstrap test (1000 replicates) is shown next to the branches. The tree is drawn to scale, with branch lengths in the same units as those of the evolutionary distances used to infer the phylogenetic tree; the scale bars indicate the number of nucleotide substitutions per site. Bootstrap values $>50 \%$ are labeled on the tree

GlaxoSmithKline) had a sero-response rate and safety profile equivalent to the only licensed MMR vaccine in the United States (MMR-II, Merck\&Co Inc.) [64, 65].

Compared with wild-type virus infection, the duration of immunity following measles vaccination has been proven to be more variable and shorter [41, 93-95]. Notably, decreasing seroprevalence in twice-vaccinated young adults has been documented, questioning the benefit of a third dose [96, 97]. 


\section{Secondary vaccine failure}

Secondary failures were first reported during the 1971 outbreak in Saint Louis in the United States in vaccinated children presenting acute-phase sera containing only IgG measles antibodies, and "modified" or "atypical" illnesses with prodromes (fever, cough and coryza) but mild symptoms and non-confluent rash [98]. A meta-analysis in 1996 evaluated the rate of secondary failure at less than $0.02 \%$ [99]. In the 1990s, cases of healthcare workers who developed measles despite pre-existing anti-measles antibody levels were emphasized [100]. During recent outbreaks, when investigated, secondary failures were documented in substantial proportions [19, 101-103]. In Japan, during an importationrelated measles outbreak in 2017, 16/60 (26\%) cases were secondary failures (mild disease without $\operatorname{IgM}$ ) infected with a D8 variant [104]. In the Netherlands, secondary vaccine failures during a measles nosocomial outbreak were documented in 8 out of 50 (16\%) twice-vaccinated exposed health workers, and two of them were proven to have adequate preexposure neutralizing antibodies [105]. Moreover, measles transmission from a twice-vaccinated individual with secondary vaccine failure to contact cases having past positive measles IgG antibody was first documented in New York in 2011 [106].

Antibody concentrations do not necessarily correlate with functional immunity. Commercially available enzyme linked immunosorbent assay kits (EIA or ELISA) do not distinguish between protective and non-protective IgG antibodies, and they usually lack standardized thresholds that reliably predict protection against infection [41, 107]. The plaque reduction neutralization assay is considered the gold standard to provide a quantitative assessment of the level of neutralizing antibodies, which must be over $120 \mathrm{mIU} /$ $\mathrm{mL}$ to confer clinical protection (WHO third international standard; NIBSC 97/648). However, this immunological bioassay is costly and time consuming, and it usually quantifies neutralizing antibodies against vaccine strains rather than circulating viruses. It is also incomplete regarding cellular response or other parameters, including the type and count of neutralized epitopes, so that new approaches and techniques are needed [88, 108].

In countries with high MCV2 coverage, such as Russia and Iran, outbreaks among highly vaccinated populations have been investigated. Atrasheuskaya et al. [5] documented cases with secondary vaccine failure who exhibited borderline levels of neutralizing antibodies towards the genotype A virus and no detectable levels towards the genotype D, which was circulating. Likewise, neutralizing antibody titres in the sera of vaccinated Iranian children were lower towards genotype B3 than towards genotypes H1, D4, and A [109]. Interestingly, Klingele et al. demonstrated major differences between sera from Luxembourgian adolescent vaccinees and sera from Nigerian women with measles-induced immunity in their capacity to neutralize a number of different measles virus strains [110]. All these data give rise to the hypothesis that the outcome of measles virus infection in vaccinated patients may be genotype-dependent.

\section{Molecular epidemiology of the virus}

\section{Virus genotype diversity}

As early as 1994, measles resurgence in the USA was attributed to imported viruses genetically distinct from vaccine strains, with the evidence that indigenous transmission of measles in the USA had stopped in 1993 [111]. Since 1990, 19 genotypes have been detected, A, B2, B3, C1, C2, D2, D3, D4, D5, D6, D7, D8, D9, D10, D11, G2, G3, H1, and $\mathrm{H} 2$ [48], while genotype A has not been endemic since 2008 when it was last detected in Maryland in the United States [112]. The global distribution of genotypes has been increasingly well documented [113]. During 2005-2015, 11 genotypes (B2, B3, D4, D5, D6, D7, D8, D9, D11, G3 and H1) were detected, and among them, B3, D4, D8, D9, and $\mathrm{H} 1$ are circulating to date [107]. Since 2009, genotype B3, which is endemic in most of the African continent, has merged in Europe, Americas, Russia, Yemen, Oman and Oceania $[112,113]$. Genotype B3 was found to be significantly more transmissible than the others [114]. During the last 10 years, genotype $\mathrm{D} 4$ has been responsible for major outbreaks in the WHO Eastern Mediterranean Region, notably in Iran, Syria, Egypt and Iraq [112]. Several D4 variants have been identified [115], including a sequent-divergent sub genotype that presents mutations in the neutralizing antigenic site resulting in resistance to human antibody neutralization [115, 116]. Genotype D8, endemic in India and previously mostly found in Southeast Asia and Oceania, has been exported to the Americas and Europe. Interestingly, among measles virus vaccine strains, the Chinese (Shangai-191) is the most divergent in terms of sequence [50], and in areas where it is in use, the molecular epidemiology appears slightly different, with the genotype $\mathrm{H} 1$ remaining predominant over time $[117,118]$.

\section{Variability in measles virus sequences}

Genetically, genotype $\mathrm{H} 1$ is close to B3, so that they are referred to as clusters [41]. However, as reported earlier with D4, within one genotype, genetic variations may result in significant antigenic drift. In 2009, Finsterbusch et al. [119] reported loss of several neutralizing epitopes in some genotype $\mathrm{H} 1$ strains, which escaped neutralization by vaccine virus-derived monoclonal antibodies (BH6 and $\mathrm{BH} 216$ ), in comparison with genotypes B3, C2, D4, D5, D6, D7 and 
D8, and the Edmonston-Zagreb vaccine strain. In that study, the neutralizing capacity of polyclonal sera from vaccinated individuals was conserved. However, in 2011, Shi et al. reported wild-type $\mathrm{H} 1$ viruses having a variation rate with regard to the Chinese vaccine strain as high as $12 \%$ in the $\mathrm{N}$ gene and $7 \%$ in the $\mathrm{H}$ gene. They used cross-neutralization assays to determine a significantly reduced (more than 4-fold) capacity of sera obtained from vaccinated infants in neutralizing these $\mathrm{H} 1$ wild-type isolates compared to vaccine strains [120].

Interestingly, $\mathrm{H} 1$ resistant variants reported by Finsterbusch et al. [119] displayed unique proline exchange to leucine at amino acid position 397 in their H proteins (P397L), resulting in the loss of the $\mathrm{H}$ protein noose epitope (HNE) targeted by BH6 and BH216. In 2009, the authors found 23 $\mathrm{H}$ protein sequences exhibiting L397 in the NCBI GenBank database, which was restricted to genotype $\mathrm{H} 1$ viruses, and one S397 in a D6 genotype virus. In 2003, Pütz et al. [121] reported that the frequency of L397 was $1.7 \%$ in the GenBank, EMBL, DDBJ and SwissProt databases. On April 24, 2019, we identified 1858 H protein sequences in GenBank. Among them, 165 (9\%) were incomplete, 1593 (85\%) harboured P397, and 61 (3\%) harboured L397, including $57 \mathrm{H1}$ genotypes but also four D8 genotypes, which were recorded from India between 2009 and 2013 (accession numbers JN995537.1, FJ387151.1, FJ387150.1, and FJ387133.1). We also found other amino acid substitutions at position 397 with alanine, glycine, asparagine, lysine, glutamine and serine. In contrast to L397, the change in A397 could enhance binding to BH216 antibodies [121]. Figure 6 shows the diversity of amino acids in the linear HNE (positions 379-410) for various circulating measles virus genotypes using the Virus Pathogen Resource (https://www.viprb rc.org/). The HNE sequence of the D8 strain isolated from the French case presented earlier displayed no particular variations, suggesting that other epitopes must be studied. In vitro, Lech et al. [45] documented the selection of mutations in different epitopes of the $\mathrm{H}$ proteins in the presence of antibodies and generated a virus that escaped to a cocktail of monoclonal antibodies.

Hence, the question arises whether 60 -year-old vaccines induce specific immunity efficiently against the whole spectrum of the current genotypes, which by definition differ in the genetic sequence of the proteins highly involved in the immune response against the virus. We suggest that variations in the immunodominant epitopes of wild-type strains have accumulated over time and might have been selected per geographical area when they helped to escape antibody
Fig. 6 Representation of amino acid diversity in the linear haemagglutinin noose epitope (HNE; positions 379-410) for various circulating measles virus genotypes. Amino acid sequences were downloaded from the Virus Pathogen Database and Analysis Resource (ViPR) website (https://www. viprbrc.org/brc/home.spg?decor ator=vipr). For the purpose of legibility of minority amino acids, a single representative of each different HNE was used per viral genotype. Representation was performed using the Logo website (http://weblo go.berkeley.edu/logo.cgi)

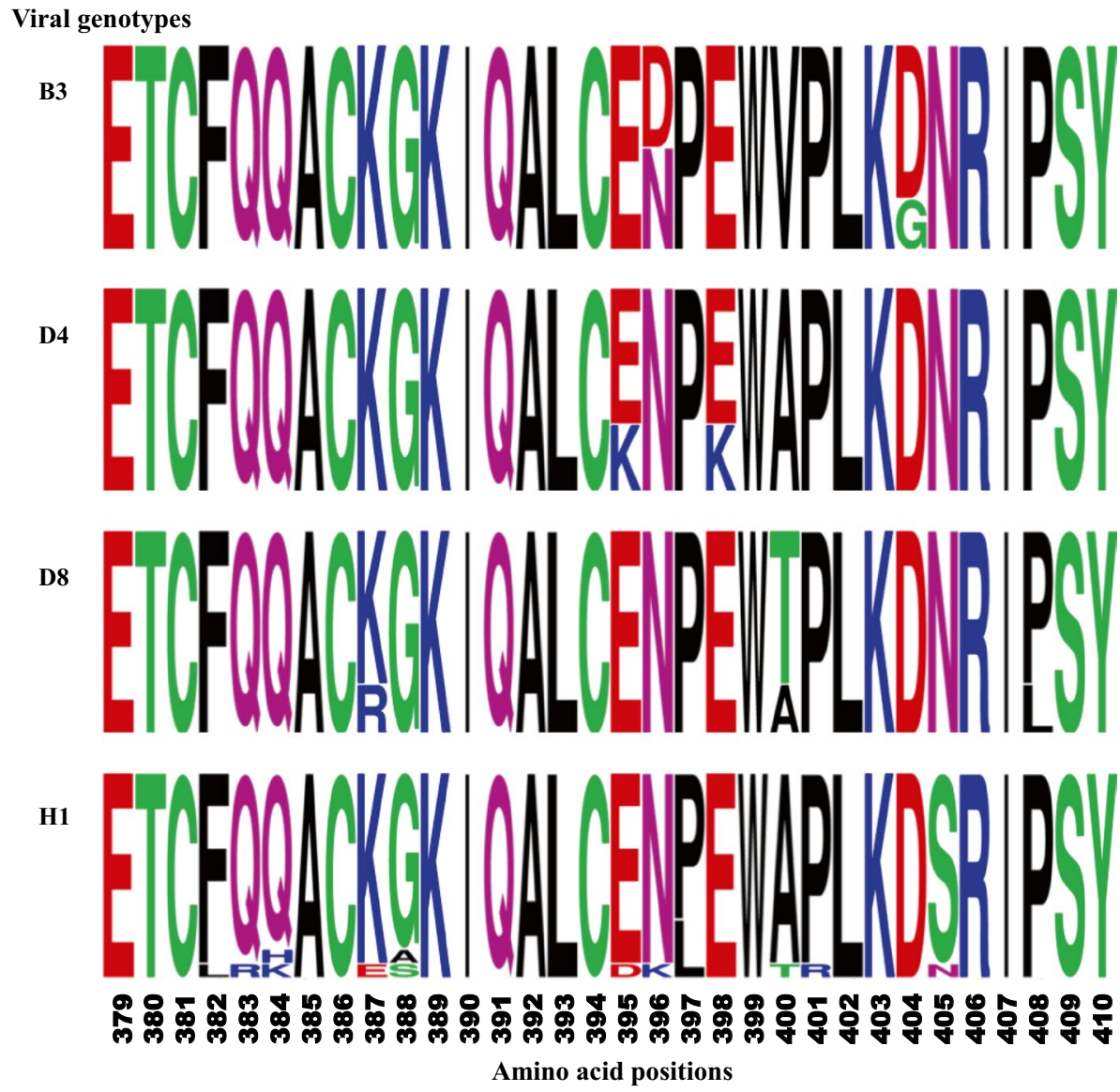


neutralization. Therefore, when introduced in areas free of endemic transmission, viral mutants evading post-vaccination immunity could emerge, similar to influenza A virus [122]. Measles vaccination may have altered viral ecology in the same way that the 7- and 13-valent vaccines against Streptococcus pneumonia have led to serotype replacement [123]. This was hypothesized in Germany in the 2000s, when a D7 emerging genotype replaced the long-term endemically circulating genotypes C2 and D6. The D7 strains exhibited substitutions of seven distinct amino acids in the $\mathrm{H}$ protein resulting in a complete loss of two neutralizing epitopes, but it was not confirmed by the results of neutralization with polyclonal sera [124]. In 2017, the H1 genotype, imported from Eastern Asia, was documented for the second time in Italy and resulted in an outbreak of 15 secondary cases, of whom two were vaccinated, but seroneutralization tests were not performed [34].

\section{Measles surveillance}

Laboratory confirmation of suspected cases is a critical component of measles surveillance, all the more to identify cases with "modified or mild disease" mimicking other illnesses, who are potential transmitters, even if the risk is considered low [125]. Serologic diagnosis using ELISAbased IgM detection may have lower specificity in low incidence setting and may be inconclusive in secondary vaccine failures. In 2000, the WHO Global Measles and Rubella Laboratory Network (GMRLN) was established to provide high-quality laboratory support for surveillance (including 723 laboratories in 164 countries as of 2018), and the CDC provides updated standards for measles molecular diagnosis and genotyping [113, 126, 127].

Assays for the molecular detection of the measles viruses in clinical samples were devised in 2006 [41, 126]. At that time, only 16 genotypes were identified, and primers/probe targeting the $\mathrm{H}$ proteins failed to detect genotype $\mathrm{B} 3$. The most efficient molecular set, still in use today, targets the $\mathrm{N}$ gene because the $\mathrm{N}$-protein is the most abundant structural protein and $\mathrm{N}$ mRNA is the most abundant viral transcript in infected cells [126, 128]. However, the $\mathrm{N}$-sequence also represents the most variable part of the genome, which is why laboratory testing requires strong technical oversight [48]. Such a possible pitfall in the molecular detection of pathogens was illustrated in 2006, when an apparent decrease in Chlamydia trachomatis infections was actually due to a new "Swedish" variant presenting a deletion that affected the target area for diagnostic tests, leading to false negative results [129].

Genetic analysis of measles viruses has been promoted and standardized by the WHO since 1998 [130]. It is a powerful approach to characterize outbreaks, track transmission pathways, and document the interruption of endemic transmission [107]. It also enables the identification of vaccine-associated cases $[128,131]$ and would be able to detect the emergence of genetically divergent vaccine-derived strains as seen with the oral polio virus [132]. Therefore, although costly and time consuming, the molecular epidemiology of circulating measles viruses must be closely monitored. However, the number of countries reporting genotype information to the Measles Nucleotide surveillance (MeaNS) database [112] is much lower than the number of countries reporting laboratory-confirmed cases (less than $50 \%$ in 2015) [113]. Moreover, genotyping is usually performed through the amplification of a nucleotide fragment of the $\mathrm{N}$ gene. This process fails in monitoring mutations in the $\mathrm{H}$ protein sequence. It would be of interest to document secondary vaccine failures by sequencing at least the $\mathrm{H}$ protein genes, if not the whole genome, to detect critical alterations in the epitope pattern. The development of nextgeneration sequencing technologies allows us to consider the implementation of more genetically exhaustive surveys, as shown, for instance, for the Ebola virus [133].

\section{Strategy proposal and key messages (Table 2)}

1. Vaccine failures across a population that has overall achieved sufficient vaccine coverage show a need for a more nuanced evaluation of vaccine coverage targets at highly localized scales, to account for clusters of high densities of un- or under-vaccinated people.

2. Vaccination regimens should be adapted to local social models and epidemiological profiles of outbreaks. In particular, the recommended age at first vaccination must balance the risk of primary failure against the risk of measles virus infection prior to vaccination. The age of first MCV dose should be lowered to 6 months in countries where children under 1 year old are the most affected, all the more if children are admitted to community infrastructures early in life, and if their mothers' immunity against measles is uncertain. This early dose should be followed by two additional doses from 12 months of age, as recommended by the New York Department of Health in areas with ongoing outbreaks [134]. Likewise, in all countries, infants aged 6-11 months should receive an "extra dose" of MMR before travelling to endemic or epidemic areas [135].

3. In the public health emergence of measles resurgence, a ring vaccination strategy to re-boost immunity and catch-up unvaccinated people, immediately after the detection of the virus, could limit its spread. To improve herd immunity, some areas such as California have also made legislation to order mandatory immunizations with sanctions if refused [136, 137]. 
4. Systematic additional dose regardless of prior immunization status [138] i.e., three or more doses, or schedules with routine booster doses, in populations at high risk of virus infection and dissemination (e.g., healthcare personnel, young adult communities, and travellers to epidemic areas) could be strategic to reduce vaccine failure and vaccinate unvaccinated people. In 2017, the ACIP recommended a third dose of mumps-containing vaccine in persons at risk during mumps outbreaks. This notably aimed at improving the titre of neutralizing antibodies against the circulating mumps virus genotype $\mathrm{G}$, which were documented to be lower than those against the genotype A vaccine strain [139]. On this occasion, it was assessed that a third dose of MMR vaccine in adults was safe [139]. In addition, Paunio et al. [86] reported during the 1988-89 measles outbreak in Finland that once and twice-vaccinated individuals had a crude relative risk of infection of 15.6 and 2.3, respectively, compared with thrice vaccinated individuals. Recently, minimal qualitative improvements in measles immune response magnitude and duration after a third MMR dose were reported in healthy young adults in the United Sates [140]. However, plaque reduction neutralization testing was performed using Edmonston measles virus, so it was not assessed if a third dose could re-boost the polyclonal immune response and clinical efficacy against the circulating genotypes.

5. There is a need to better explore HLA mediated processes and viral mutations that could play a role in primary and secondary vaccine failures. New approaches for measles vaccines should be considered, such as using a mixture of current viral variants that display diverse $\mathrm{H}$ epitopes to induce a wide-spectrum immune response.

\section{Conclusion}

According to Red Queen's hypothesis coined by Leigh van Valen in 1973 [141], every organism does the best it can adapt in the face of environmental pressures. Thus, as a result of vaccine efficiency towards the endemo-epidemic viral clade $\mathrm{A}$, mutations in measles virus genomes that allow for the evasion of neutralization by vaccine-induced antibodies have been conserved. The polyclonal nature of post-vaccine immunity has retained some efficiency but is less strong than immunity following natural infection. As vaccine-evading viral mutants are selected, vaccine failures due to imported genotypes in non-endemic areas are increasing. Disease extinction can only occur if all strains are as efficiently neutralized over a very long time interval. The Red Queen's theory should keep in mind that in the field of infectious diseases, adversaries are not stable but can change and improve, and no success is definitive. Hence, to meet the goal of measles eradication, all viral variants in their adaptative zone must be targeted, host determinants of vaccine response must be considered, and vaccine policies must be adapted to achieve sufficient level of high-quality and longterm immunity in all age groups.

Table 2 Major arguments and themes of this review, and related main references

\begin{tabular}{|c|c|}
\hline Arguments/themes & References \\
\hline $\begin{array}{l}\text { There are weaknesses regarding measles vaccine coverage targets, reports, and the correlation } \\
\text { with the risk of measles outbreak due to: }\end{array}$ & $\begin{array}{l}{[5,6,9,10]} \\
{[11,12]}\end{array}$ \\
\hline Non-optimal methods for vaccine coverage evaluation & {$[10,14-21]$} \\
\hline $\begin{array}{l}\text { Children younger than } 12-15 \text { months: they are under the age recommended for first vaccination } \\
\text { but increasingly account for measles cases }\end{array}$ & {$[22-27]$} \\
\hline \multicolumn{2}{|l|}{$\begin{array}{l}\text { Clusters of unvaccinated or under-vaccinated people among populations achieving overall suf- } \\
\text { ficient coverage }\end{array}$} \\
\hline $\begin{array}{l}\text { Measles vaccines are 60-year-old and contain viral strains belonging to the clade A, no more } \\
\text { detected since } 2008\end{array}$ & [112] \\
\hline $\begin{array}{l}\text { Measles live-attenuated vaccine is not as immunogenic as natural infection (primary failure) due } \\
\text { to host factors (age, HLA), and vaccine-induced immunity is waning with time. At least } 2 \text { doses } \\
\text { are recommended at all ages }\end{array}$ & {$[36,41,52,53,57,74,78,79,86-89,93-97]$} \\
\hline $\begin{array}{l}\text { Post-vaccination antibodies may be not protective against some strains (secondary failures). } \\
\text { Highly exposed population (healthcare workers, travellers) are of particular concern }\end{array}$ & {$[5,98-106,109,110]$} \\
\hline Measles virus antigenic stability is probably not an enduring rule & {$[44,45,49,115-121,124]$} \\
\hline $\begin{array}{l}\text { Some recent measles variants have been demonstrated able to evade antibody-mediated neutrali- } \\
\text { zation }\end{array}$ & {$[45,109,110,114-116,119,120,124]$} \\
\hline $\begin{array}{l}\text { Measles virus molecular epidemiology based on genotyping targeting the } \mathrm{N} \text {-gene misses the } \\
\text { detection of mutations in the } \mathrm{H} \text { and } \mathrm{F} \text { genes that encode epitopes involved in the host response } \\
\text { to the virus }\end{array}$ & {$[40,43,107,127]$} \\
\hline
\end{tabular}


Author contribution All authors contributed to the review conception and design. Emilie Javelle made the literature search. Philippe Colson achieved virology laboratory testing presented in the article, and built some figures. Philippe Parola clinically managed the case of vaccine failure, helped in the study design and data collection. Didier Raoult had the idea for the article, reviewed data analyses and provided data interpretation. The first draft was written by Emilie Javelle and all authors commented on previous versions of the manuscript and critically revised the work. All authors read and approved the final manuscript.

Funding This study was not funded.

\section{Compliance with ethical standards}

Conflict of interest The authors declare that that they have no potential conflict of interest.

\section{References}

1. Hopkins DR, Hinman AR, Koplan JP, Lane JM. The case for global measles eradication. Lancet. 1982;1:1396-8.

2. WHO. Global Vaccine Action Plan 2011-2020. http://www. who.int/immunization/global_vaccine_action_plan/GVAP_ doc_2011_2020/en/. Accessed 10 April 2019.

3. WHO. Data, statistics and graphics. http://www.who.int/immun ization/monitoring_surveillance/data/en/. Accessed 7 April 2019.

4. Ministerio de Salud activa protocolo ante caso sospechoso de sarampión. https://www.ministeriodesalud.go.cr/index.php/noticias/ noticias-2019/1397-ministerio-de-salud-activa-protocolo-antecaso-sospechoso-de-sarampion. Accessed 10 April 2019.

5. Atrasheuskaya AV, Kulak MV, Neverov AA, Rubin S, Ignatyev GM. Measles cases in highly vaccinated population of Novosibirsk, Russia, 2000-2005. Vaccine. 2008;26:2111-8.

6. Breakwell L, Moturi E, Helgenberger L, et al. Measles outbreak associated with vaccine failure in adults-Federated States Of Micronesia, February-August 2014. MMWR Morb Mortal Wkly Rep. 2015;64:1088-92.

7. Rosenthal SR, Clements CJ. Two-dose measles vaccination schedules. Bull World Health Organ. 1993;71:421-8.

8. Hethcote HW. Measles and rubella in the United States. Am J Epidemiol. 1983;117:2-13.

9. Funk S, Knapp JK, Lebo E, et al. Combining serological and contact data to derive target immunity levels for achieving and maintaining measles elimination. bioRxiv 2019;201574 (not peer reviewed)

10. Orsoo O, Saw YM, Sereenen E, et al. Epidemiological characteristics and trends of a Nationwide measles outbreak in Mongolia, 2015-2016. BMC Public Health. 2019;19:201.

11. WHO. WHO/UNICEF Joint Reporting Process. http://www.who. int/immunization/monitoring_surveillance/routine/reporting/en/. Accessed 7 April 2019.

12. Irons B, Dobbins JG. Caribbean vaccine managers. The Caribbean experience in maintaining high measles vaccine coverage. J Infect Dis. 2011;204(Suppl 1):S284-8.

13. WHO. Vaccination coverage cluster survey. https://www.who. int/immunization/monitoring_surveillance/Vaccination_cover age_cluster_survey_with_annexes.pdf?ua=1. Accessed 19 April 2019.

14. Santé Publique France-INVS. Points d'actualités Rougeole. http://invs.santepubliquefrance.fr/Dossiers-thematiques/Malad ies-infectieuses/Maladies-a-declaration-obligatoire/Rougeole/ Points-d-actualites. Accessed 28 April 2019.
15. Muscat M, Marinova L, Mankertz A, et al. The measles outbreak in Bulgaria, 2009-2011: an epidemiological assessment and lessons learnt. Euro Surveill. 2016;21:30152.

16. George F, Valente J, Augusto GF, et al. Measles outbreak after 12 years without endemic transmission, Portugal, February to May 2017. Euro Surveill. 2017;22:30548.

17. Lancella L, Di Camillo C, Vittucci AC, Boccuzzi E, Bozzola E, Villani A. Measles lessons in an anti-vaccination era:public health is a social duty, not a political option. Ital J Pediatr. 2017;43:102.

18. Muscat M, Ben Mamou M, Singh S, et al. Elimination of measles in the WHO European region-challenges persist. Bundesgesundheitsblatt Gesundheitsforschung Gesundheitsschutz. 2019;62:440-9 [Article in German].

19. Han K, Chen S, Tang C, et al. The epidemiological and serological characteristics of measles in Dongguan, China, 2005-2014. Hum Vaccines Immunother. 2016;12:2181-7.

20. Pan American Health Organization/World Health Organization. Epidemiological update: measles. 4 March 2019. https://www. paho.org/hq/index.php?option=com_docman\&view $=$ downl oad\&category_slug $=$ measles $-2204 \&$ alias $=47907-4$ - march -2019-measles-epidemiological-update\&Itemid=270\&lang=en. Accessed 28 April 2019.

21. WHO. Measles-Brazil. 11 June 2018. http://www.who.int/csr/ don/11-june-2018-measles-brazil/en/. Accessed 28 April 2019.

22. Gastañaduy PA, Budd J, Fisher N, et al. A measles outbreak in an underimmunized Amish Community in Ohio. N Engl J Med. 2016;375:1343-54.

23. Pager T, Mays JC. New York declares measles emergency, requiring vaccinations in parts of Brooklyn. N. Y. Times. 2019; published online April 10. https://www.nytimes.com/2019/04/09/ nyregion/measles-vaccination-williamsburg.html. Accessed 14 April 2019.

24. de Munter AC, Tostmann A, Hahné SJM, Spaan DH, van Ginkel R, Ruijs WLM. Risk factors for persisting measles susceptibility:a case-control study among unvaccinated orthodox Protestants. Eur J Public Health. 2018;28:922-7.

25. Godefroy R, Chaud P, Ninove L, et al. Measles outbreak in a French Roma community in the Provence-Alpes-Côte d'Azur region, France, May to July 2017. Int J Infect Dis. 2018;76:97-101.

26. Komitova R, Kevorkyan A, Boykinova O, et al. Difficulties in achieving and maintaining the goal of measles elimination in Bulgaria. Rev Epidemiol Sante Publique. 2019;67:155-62.

27. Phadke VK, Bednarczyk RA, Salmon DA, Omer SB. Association between vaccine refusal and vaccine-preventable diseases in the United States: a review of measles and pertussis. JAMA. 2016;315:1149-58.

28. Wadman M. Measles cases have tripled in Europe, fueled by Ukrainian outbreak. Sci. AAAS. 2019; published online Feb 12. https://www.sciencemag.org/news/2019/02/measles-cases -have-tripled-europe-fueled-ukrainian-outbreak. Accessed 15 May 2019.

29. Cousins S. Measles: a global resurgence. Lancet Infect Dis. 2019;19:362-3.

30. Obradovic Z, Balta S, Obradovic A, Mesic S. The impact of war on vaccine preventable diseases. Mater Socio-Medica. 2014;26:382-4.

31. El Bcheraoui C, Jumaan AO, Collison ML, Daoud F, Mokdad $\mathrm{AH}$. Health in Yemen: losing ground in war time. Glob Health. 2018;14:42.

32. Paniz-Mondolfi AE, Tami A, Grillet ME, et al. Resurgence of vaccine-preventable diseases in Venezuela as a regional public health threat in the Americas. Emerg Infect Dis. 2019;25:625-32.

33. Lee AD, Clemmons NS, Patel M, Gastañaduy PA. International importations of measles virus into the United States 
during the Post-Elimination Era, 2001-2016. J Infect Dis. 2018;219:1616-23.

34. Rovida F, Brianese N, Piralla A, et al. Outbreak of measles genotype $\mathrm{H} 1$ in Northern Italy originated from a case imported from Southeast Asia, 2017. Clin Microbiol Infect. 2019;25:526-8.

35. Plans-Rubió P. Evaluation of the establishment of herd immunity in the population by means of serological surveys and vaccination coverage. Hum Vaccines Immunother. 2012;8:184-8.

36. Leong WY. Measles cases hit record high in Europe in 2018. J Travel Med. 2018. https://doi.org/10.1093/jtm/tay080.

37. Enders JF, Peebles TC. Propagation in tissue cultures of cytopathogenic agents from patients with measles. Proc Soc Exp Biol Med. 1954;86:277-86.

38. Katz SL, Kempe CH, Black FL, et al. Studies on an attenuated measles-virus vaccine. N Engl J Med. 1960;263:180-4.

39. WHO. Immunological basis for immunization: measles (Update 2009). https://www.who.int/immunization/documents/ISBN9 789241597555/en/. Accessed 10 April 2019.

40. de Swart RL, Yüksel S, Osterhaus ADME. Relative contributions of measles virus hemagglutinin- and fusion proteinspecific serum antibodies to virus neutralization. J Virol. 2005;79:11547-51.

41. Bellini WJ, Rota PA. Biological feasibility of measles eradication. Virus Res. 2011;162:72-9.

42. Fulton BO, Sachs D, Beaty SM, et al. Mutational analysis of measles virus suggests constraints on antigenic variation of the glycoproteins. Cell Rep. 2015;11:1331-8.

43. Tahara M, Bürckert J-P, Kanou K, Maenaka K, Muller CP, Takeda M. Measles virus hemagglutinin protein epitopes: the basis of antigenic stability. Viruses. 2016;8:216.

44. Tamin A, Rota PA, Wang ZD, Heath JL, Anderson LJ, Bellini WJ. Antigenic analysis of current wild type and vaccine strains of measles virus. J Infect Dis. 1994;170:795-801.

45. Lech PJ, Tobin GJ, Bushnell R, et al. Epitope dampening monotypic measles virus hemagglutinin glycoprotein results in resistance to cocktail of monoclonal antibodies. PLoS ONE. 2013;8:e52306.

46. Rota WJB, Rota PA. Genetic diversity of wild-type measles viruses: implications for global measles elimination programs. Emerg Infect Dis. 1998;4:29-34.

47. WHO. Nomenclature for describing the genetic characteristics of wild-type measles viruses (update). Part I. Wkly Epidemiol Rec. 2001;76:242-7.

48. CDC. Measles. Genetic analysis of measles virus. Lab Tools. 2019; published online Feb 26. https://www.cdc.gov/measles/ lab-tools/genetic-analysis.html. Accessed 10 April 2019.

49. Bankamp B, Lopareva EN, Kremer JR, et al. Genetic variability and mRNA editing frequencies of the phosphoprotein genes of wild-type measles viruses. Virus Res. 2008;135:298-306.

50. Rota JS, Zhong-De W, Rota PA, Bellini WJ. Comparison of sequences of the $\mathrm{H}, \mathrm{F}$, and $\mathrm{N}$ coding genes of measles virus vaccine strains. Virus Res. 1994;31:317-30.

51. Demicheli V, Rivetti A, Debalini MG, Di Pietrantonj C. Vaccines for measles, mumps and rubella in children. Cochrane Database Syst Rev 2012;15:Cd004407.

52. Advisory Committee on Immunization Practices, Centers for Disease Control and Prevention (CDC). Immunization of healthcare personnel: recommendations of the Advisory Committee on Immunization Practices (ACIP). MMWR. 2011;60:1-45.

53. Uzicanin A, Zimmerman L. Field effectiveness of live attenuated measles-containing vaccines: a review of published literature. J Infect Dis. 2011;204(Suppl 1):S133-48.

54. Yeung LF, Lurie P, Dayan G, et al. A limited measles outbreak in a highly vaccinated US boarding school. Pediatrics. 2005;116:1287-91.
55. Lee MS, Lee LL, Chen HY, Wu YC, Horng CB. Post mass-immunization measles outbreak in Taoyuan County, Taiwan:dynamics of transmission, vaccine effectiveness, and herd immunity. Int $\mathbf{J}$ Infect Dis. 1998;3:64-9.

56. Doshi S, Khetsuriani N, Zakhashvili K, Baidoshvili L, Imnadze $\mathrm{P}$, Uzicanin A. Ongoing measles and rubella transmission in Georgia, 2004-05: implications for the national and regional elimination efforts. Int J Epidemiol. 2009;38:182-91.

57. Akramuzzaman SM, Cutts FT, Hossain MJ, et al. Measles vaccine effectiveness and risk factors for measles in Dhaka, Bangladesh. Bull World Health Organ. 2002;80:776-82.

58. Pillsbury A, Quinn H. An assessment of measles vaccine effectiveness, Australia, 2006-2012. West Pac Surveill Response J. 2015;6:43-50.

59. Kuter BJ, Brown M, Wiedmann RT, Hartzel J, Musey L. Safety and immunogenicity of M-M-RII (Combination MeaslesMumps-Rubella Vaccine) in clinical trials of healthy children conducted between 1988 and 2009. Pediatr Infect Dis J. 2016;35:1011-20.

60. Fazilli A, Mir AA, Shah RJ, Bhat IA, Fomda BA, Bhat MA. Effect of second dose of measles vaccine on measles antibody status:a randomized controlled trial. Indian Pediatr. 2013;50:473-6.

61. MMR-158 Study Group. A second dose of a measles-mumpsrubella vaccine administered to healthy four-to-six-year-old children:a phase III, observer-blind, randomized, safety and immunogenicity study comparing GSK MMR and MMR II with and without DTaP-IPV and varicella vaccines co-administration. Hum Vaccines Immunother. 2019;15:1-14.

62. MMR-161 Study Group. Immunogenicity and safety of measlesmumps-rubella vaccine at two different potency levels administered to healthy children aged 12-15 months:A phase III, randomized, non-inferiority trial. Vaccine. 2018;36:5781-8.

63. MMR-162 Study Group. Safety and immunogenicity of an upperrange release titer measles-mumps-rubella vaccine in children vaccinated at $12-15$ months of age: a phase III, randomized study. Hum Vaccines Immunother. 2018;14:1-11.

64. Klein NP, Abu-Elyazeed R, Povey M, et al. Immunogenicity and safety of a measles-mumps-rubella vaccine administered as a first dose to children aged 12-15 months: a phase III, randomized, noninferiority, lot-to-lot consistency study. J Pediatr Infect Dis Soc. 2019. https://doi.org/10.1093/jpids/piz010.

65. Abu-Elyazeed R, Jennings W, Severance R, et al. Immunogenicity and safety of a second dose of a measles-mumps-rubella vaccine administered to healthy participants 7 years of age or older: a phase III, randomized study. Hum Vaccines Immunother. 2018;14:2624-31.

66. MVDP author group, Cape S, Chaudhari A, et al. Safety and immunogenicity of dry powder measles vaccine administered by inhalation: a randomized controlled Phase I clinical trial. Vaccine. 2014;32:6791-7.

67. Huang L-M, Lee B-W, Chan PC, Povey M, Henry O. Immunogenicity and safety of combined measles-mumps-rubellavaricella vaccine using new measles and rubella working seeds in healthy children in Taiwan and Singapore. Hum Vaccines Immunother. 2013;9:1308-15.

68. Berry AA, Abu-Elyazeed R, Diaz-Perez C, et al. Two-year antibody persistence in children vaccinated at $12-15$ months with a measles-mumps-rubella virus vaccine without human serum albumin. Hum Vaccines Immunother. 2017;13:1516-22.

69. Mufson MA, Diaz C, Leonardi M, et al. Safety and immunogenicity of human serum albumin-free MMR vaccine in US children aged 12-15 months. J Pediatr Infect Dis Soc. 2015;4:339-48.

70. Fisker AB, Nebie E, Schoeps A, et al. A two-center randomized trial of an additional early dose of measles vaccine: effects 
on mortality and measles antibody levels. Clin Infect Dis. 2018;66:1573-80.

71. Brond M, Martins CL, Byberg S, et al. Randomized trial of 2 versus 1 dose of measles vaccine: effect on hospital admission of children after 9 months of age. J Pediatr Infect Dis Soc. 2018;7:226-33.

72. Schoeps A, Nebié E, Fisker AB, et al. No effect of an additional early dose of measles vaccine on hospitalization or mortality in children: a randomized controlled trial. Vaccine. 2018;36:1965-71.

73. Krause PJ, Gross PA, Barrett TL, et al. Quality standard for assurance of measles immunity among health care workers. The Infectious Diseases Society of America. Infect Control Hosp Epidemiol. 1994;15:193-9.

74. Steingart KR, Thomas AR, Dykewicz CA, Redd SC. Transmission of measles virus in healthcare settings during a communitywide outbreak. Infect Control Hosp Epidemiol. 1999;20:115-9.

75. Lake JG, Luvsansharav U-O, Hagan JE, et al. Healthcare-associated measles after a nationwide outbreak in Mongolia. Clin Infect Dis. 2018;67:288-90.

76. Botelho-Nevers E, Gautret P, Biellik R, Brouqui P. Nosocomial transmission of measles: an updated review. Vaccine. 2012;30:3996-4001.

77. Fiebelkorn AP, Redd SB, Kuhar DT. Measles in healthcare facilities in the United States during the postelimination Era, 2001-2014. Clin Infect Dis. 2015;61:615-8.

78. Patel MK, Orenstein WA. Classification of global measles cases in 2013-17 as due to policy or vaccination failure: a retrospective review of global surveillance data. Lancet Glob Health. 2019;7:313-20.

79. Cherry JD, Zahn M. Clinical characteristics of measles in previously vaccinated and unvaccinated patients in California. Clin Infect Dis. 2018;67:1315-9.

80. Paunio M, Hedman K, Davidkin I, et al. Secondary measles vaccine failures identified by measurement of IgG avidity: high occurrence among teenagers vaccinated at a young age. Epidemiol Infect. 2000;124:263-71.

81. Kakoulidou M, Ingelman-Sundberg H, Johansson E, et al. Kinetics of antibody and memory B cell responses after MMR immunization in children and young adults. Vaccine. 2013;31:711-7.

82. Carazo Perez S, De Serres G, Bureau A, Skowronski DM. Reduced antibody response to infant measles vaccination: effects based on type and timing of the first vaccine dose persist after the second dose. Clin Infect Dis. 2017;65:1094-102.

83. Meeting of the Strategic Advisory Group of Experts on Immunization. Conclusions and recommendations. Releve Epidemiol Hebd. 2015;2015(90):681-99.

84. Gans H, Yasukawa L, Rinki M, et al. Immune responses to measles and mumps vaccination of infants at 6,9 , and 12 months. $\mathrm{J}$ Infect Dis. 2001;184:817-26.

85. CDC. Measles prevention: recommendations of the immunization practices Advisory Committee (ACIP). https://www.cdc. gov/Mmwr/preview/mmwrhtml/00041753.htm. Accessed 10 April 2019.

86. Paunio M, Peltola H, Valle M, Davidkin I, Virtanen M, Heinonen OP. Twice vaccinated recipients are better protected against epidemic measles than are single dose recipients of measles containing vaccine. J Epidemiol Community Health. 1999;53:173-8.

87. De Serres G, Boulianne N, Defay F, et al. Higher risk of measles when the first dose of a 2-dose schedule of measles vaccine is given at 12-14 months versus 15 months of age. Clin Infect Dis. 2012;55:394-402.

88. Haralambieva IH, Kennedy RB, Ovsyannikova IG, Whitaker JA, Poland GA. Variability in humoral immunity to measles vaccine: new developments. Trends Mol Med. 2015;21:789-801.
89. Gomber S, Arora SK, Das S, Ramachandran VG. Immune response to second dose of MMR vaccine in Indian children. Indian J Med Res. 2011;134:302-6.

90. Li Y, Chu SY, Yue C, et al. Immunogenicity and safety of measles-rubella vaccine co-administered with attenuated Japanese encephalitis SA 14-14-2 vaccine in infants aged 8 months in China: a non-inferiority randomised controlled trial. Lancet Infect Dis. 2019;19:402-9.

91. Clifford HD, Hayden CM, Khoo S-K, et al. Genetic variants in the IL-4/IL-13 pathway influence measles vaccine responses and vaccine failure in children from Mozambique. Viral Immunol. 2017;30:472-8.

92. Izadi S, Zahraei SM, Salehi M, Mohammadi M, Tabatabaei SM, Mokhtari-Azad T. Head-to-head immunogenicity comparison of Edmonston-Zagreb vs. AIK-C measles vaccine strains in infants aged 8-12 months: a randomized clinical trial. Vaccine. 2018;36:631-6.

93. Markowitz LE, Preblud SR, Fine PE, Orenstein WA. Duration of live measles vaccine-induced immunity. Pediatr Infect Dis J. 1990;9:101-10.

94. Krugman S. Present status of measles and rubella immunization in the United States: a medical progress report. J Pediatr. 1977;90:1-12.

95. Kennedy RB, Ovsyannikova IG, Thomas A, Larrabee BR, Rubin $\mathrm{S}$, Poland GA. Differential durability of immune responses to measles and mumps following MMR vaccination. Vaccine. 2019;37:1775-84.

96. Poethko-Müller C, Mankertz A. Seroprevalence of measles-, mumps- and rubella-specific IgG antibodies in German children and adolescents and predictors for seronegativity. PLoS ONE. 2012;7:42867.

97. Kim S-K, Park H-Y, Kim S-H. A third dose of measles vaccine is needed in young Korean health care workers. Vaccine. 2018;36:3888-9.

98. Cherry JD, Feigin RD, Shackelford PG, Hinthorn DR, Schmidt RR. A clinical and serologic study of 103 children with measles vaccine failure. J Pediatr. 1973;82:802-8.

99. Anders JF, Jacobson RM, Poland GA, Jacobsen SJ, Wollan PC. Secondary failure rates of measles vaccines: a metaanalysis of published studies. Pediatr Infect Dis J. 1996;15:62.

100. Ammari LK, Bell LM, Hodinka RL. Secondary measles vaccine failure in healthcare workers exposed to infected patients. Infect Control Hosp Epidemiol. 1993;14:81-6.

101. Pannuti CS, Morello RJ, de Moraes JC, et al. Identification of primary and secondary measles vaccine failures by measurement of immunoglobulin $\mathrm{G}$ avidity in measles cases during the 1997 São Paulo epidemic. Clin Diagn Lab Immunol. 2004;11:119-22.

102. Santibanez S, Prosenc K, Lohr D, et al. Measles virus spread initiated at international mass gatherings in Europe, 2011. Euro Surveill 2014;19(35):20891.

103. Orosz L, Gáspár G, Rózsa Á, Rákos N, Sziveri S, Bosnyákovits T. Epidemiological situation of measles in Romania, Italy, and Hungary: on what threats should we focus nowadays? Acta Microbiol Immunol Hung. 2018;65:127-34.

104. Komabayashi K, Seto J, Tanaka S, et al. The largest measles outbreak, including 38 modified measles and 22 typical measles cases in its elimination Era in Yamagata, Japan, 2017. Jpn J Infect Dis. 2018;71:413-8.

105. Hahné SJM, Nic Lochlainn LM, van Burgel ND, et al. Measles outbreak among previously immunized healthcare workers, The Netherlands, 2014. J Infect Dis. 2016;214:1980-6.

106. Rosen JB, Rota JS, Hickman CJ, et al. Outbreak of measles among persons with prior evidence of immunity, New York City, 2011. Clin Infect Dis. 2014;58:1205-10.

107. WHO. Manual for the Laboratory-based Surveillance of Measles, Rubella, and Congenital Rubella Syndrome. http://www.who.int/ 
immunization/monitoring_surveillance/burden/laboratory/manua 1_chapter7/en/. Accessed 18 April 2019.

108. Haralambieva IH, Kennedy RB, Ovsyannikova IG, Schaid DJ, Poland GA. Current perspectives in assessing humoral immunity after measles vaccination. Expert Rev Vaccines. 2019;18:75-87.

109. Fatemi Nasab GS, Salimi V, Abbasi S, Adjami Nezhad Fard F, Mokhtari Azad T. Comparison of neutralizing antibody titers against outbreakassociated measles genotypes (D4, H1 and B3) in Iran. Pathog Dis. 2016;74:ftw089.

110. Klingele M, Hartter HK, Adu F, Ammerlaan W, Ikusika W, Muller CP. Resistance of recent measles virus wild-type isolates to antibody-mediated neutralization by vaccinees with antibody. $\mathbf{J}$ Med Virol. 2000;62:91-8.

111. Bellini W. Genetic diversity of wild-type measles viruses: implications for global measles elimination programs. Emerg Infect Dis. 1998;4:29-35.

112. Rota PA, Brown K, Mankertz A, et al. Global distribution of measles genotypes and measles molecular epidemiology. J Infect Dis. 2011;204(Suppl 1):S514-23.

113. Mulders MN, Rota PA, Icenogle JP, et al. Global measles and rubella laboratory network support for elimination goals, 20102015. MMWR. 2016;65:438-42.

114. Ackley SF, Hacker JK, Enanoria WTA, et al. Genotype-specific measles transmissibility: a branching process analysis. Clin Infect Dis. 2018;66:1270-5.

115. Gil H, Fernández-García A, Mosquera MM, et al. Measles virus genotype D4 strains with non-standard length M-F non-coding region circulated during the major outbreaks of 2011-2012 in Spain. PLoS ONE. 2018;13:e0199975.

116. Muñoz-Alía MÁ, Muller CP, Russell SJ. Antigenic drift defines a new D4 subgenotype of measles virus. J Virol. 2017;91:e00209-17.

117. Xu S, Zhang Y, Rivailler P, et al. Evolutionary genetics of genotype H1 measles viruses in China from 1993 to 2012. J Gen Virol. 2014;95:1892-9.

118. Xu W, Tamin A, Rota JS, Zhang L, Bellini WJ, Rota PA. New genetic group of measles virus isolated in the People's Republic of China. Virus Res. 1998;54:147-56.

119. Finsterbusch T, Wolbert A, Deitemeier I, et al. Measles viruses of genotype $\mathrm{H} 1$ evade recognition by vaccine-induced neutralizing antibodies targeting the linear haemagglutinin noose epitope. J Gen Virol. 2009;90:2739-45.

120. Shi J, Zheng J, Huang H, et al. Measles incidence rate and a phylogenetic study of contemporary genotype $\mathrm{H} 1$ measles strains in China: is an improved measles vaccine needed? Virus Genes. 2011;43:319-26.

121. Pütz MM, Hoebeke J, Ammerlaan W, Schneider S, Muller CP. Functional fine-mapping and molecular modeling of a conserved loop epitope of the measles virus hemagglutinin protein. Eur $\mathbf{J}$ Biochem. 2003;270:1515-27.

122. Zharikova D, Mozdzanowska K, Feng J, Zhang M, Gerhard W. Influenza type A virus escape mutants emerge in vivo in the presence of antibodies to the ectodomain of matrix protein $2 . \mathrm{J}$ Virol. 2005;79:6644-54.

123. Weinberger DM, Malley R, Lipsitch M. Serotype replacement in disease following pneumococcal vaccination: a discussion of the evidence. Lancet. 2011;378:1962-73.

124. Santibanez S, Niewiesk S, Heider A, et al. Probing neutralizing-antibody responses against emerging measles viruses (MVs):immune selection of MV by $\mathrm{H}$ protein-specific antibodies? J Gen Virol. 2005;86:365-74.
125. Béraud G, Abrams S, Beutels P, Dervaux B, Hens N. Resurgence risk for measles, mumps and rubella in France in 2018 and 2020. Euro Surveill. 2018;23:1700796.

126. Hummel KB, Lowe L, Bellini WJ, Rota PA. Development of quantitative gene-specific real-time RT-PCR assays for the detection of measles virus in clinical specimens. J Virol Methods. 2006;132:166-73.

127. Bankamp B, Byrd-Leotis LA, Lopareva EN, et al. Improving molecular tools for global surveillance of measles virus. J Clin Virol. 2013;58:176-82.

128. Roy F, Mendoza L, Hiebert J, et al. Rapid identification of measles virus vaccine genotype by real-time PCR. J Clin Microbiol. 2017;55:735-43.

129. Ripa T, Nilsson P. A variant of Chlamydia trachomatis with deletion in cryptic plasmid: implications for use of PCR diagnostic tests. Euro Surveill. 2006;11:3076.

130. WHO. Standardization of the nomenclature for describing the genetic characteristics of wild-type measles viruses. Weekly Epidemiol Rec. 1998;73:265-72.

131. Murti M, Krajden M, Petric M, et al. Case of vaccine-associated measles five weeks post-immunisation, British Columbia, Canada, October 2013. Euro Surveill. 2013;18:20649.

132. Jorba J, Diop OM, Iber J, et al. Update on vaccine-derived polioviruses-worldwide, January 2017-June 2018. MMWR. 2018;67:1189-94.

133. Quick J, Loman NJ, Duraffour S, et al. Real-time, portable genome sequencing for Ebola surveillance. Nature. 2016;530:228-32.

134. Barbot O. New York City Department of Health and Mental Hygiene. Order of the Commissioner. 9 April 2019. https://child renshealthdefense.org/wp-content/uploads/emergency-order s-measles-1.pdf. Accessed 28 April 2019.

135. Heywood AE. Measles: a re-emerging problem in migrants and travellers. J Travel Med. 2018. https://doi.org/10.1093/jtm/tay11 8.

136. Becker R. How measles snuck into California despite strict vaccine legislation. The Verge. 2019; published online Feb 28. https ://www.theverge.com/2019/2/28/18245084/measles-california -cdc-outbreak-vaccination-legislation. Accessed 28 April 2019.

137. Barraza L, Schmit C, Hoss A. The latest in vaccine policies: selected issues in school vaccinations, healthcare worker vaccinations, and pharmacist vaccination authority laws. J Law Med Ethics. 2017;45:16-9.

138. McKee A, Ferrari MJ, Shea K. Correlation between measles vaccine doses:implications for the maintenance of elimination. Epidemiol Infect. 2018;146:468-75.

139. Marin M. Recommendation of the advisory committee on immunization practices for use of a third dose of mumps virus-containing vaccine in persons at increased risk for mumps during an outbreak. MMWR. 2018;67:33-8.

140. Fiebelkorn AP, Coleman LA, Belongia EA, et al. Measles virus neutralizing antibody response, cell-mediated immunity, and IgG antibody avidity before and after a third dose of measles-mumpsrubella vaccine in young adults. J Infect Dis. 2016;213:1115-23.

141. Van Valen L. A new evolutionary law. Evol Therory. 1973;1:1-30.

Publisher's Note Springer Nature remains neutral with regard to jurisdictional claims in published maps and institutional affiliations. 